\title{
Domains and CauseP in a unified semantics of Chinese adverbial ziji 'self'
}

\author{
Hsiu-Chen Daphne Liao \\ National Chiao Tung University, Taiwan \\ h.c.daphne.liao@gmail.com
}

\begin{abstract}
A unified semantics of Chinese adverbial ziji 'self' is proposed for its three exclusive readings. In the proposal, adverbial ziji is a focused item, evoking alternatives for consideration by its focus semantic value. Depending on domain variation and different syntactic adjoining positions, ziji shows various surface readings, though the availability of readings is affected by context, world knowledge, and a relation presupposition triggered by ziji. The proposed mechanism suggests the following. First, CauseP for internal causation cannot be introduced by ziji, but is projected more prevalently than commonly assumed. Second, CauseP should be projected in anticausatives. If this analysis is on the right track, it will give us a new perspective of intensifiers and the projection of CauseP, and it will also help us advance the study of anticausatives.
\end{abstract}

Keywords: intensifier; reflexive marker; anticausative; causation; group

\section{Introduction}

It has been pointed out that reflexive markers have various uses crosslinguistically (cf. Kemmer 1993; König \& Siemund 2000; Heine 2000; Siemund 2000; König 2001; among many others). For example, the Chinese reflexive marker ziji can appear in an argument position as a reflexive anaphor (as in (1)), or it may function as the so-called reflexive intensifier in its adverbial use (as in (2)).

(1) Zhangsan da-le ziji yi xia.

Reflexive anaphor

Zhangsan hit-PFV ZIJI one CLF

'Zhangsan hit himself once.'

(2) A: Did Bill send the letter for John?

Reflexive intensifier

B: Meiyou, John ziji ji-le xin.

(non-delegation reading)

No, John ZIJI send-PFV letter

'No, John sent the letter himself.' 
Note that in (2), ziji expresses that John acted to perform the event described, rather than asking some other person to do it. This sort of meaning is called the 'non-delegation' reading in previous works, such as Constantinou (2014).

A reflexive marker may also be used to mark a construction where a verb with transitive/intransitive uses is used intransitively. For example, in addition to its anaphoric use, Italian si is used to mark the socalled middle construction in (3) and the anticausative construction in (4). ${ }^{1}$

(3) Questo tavolino si trasporta facilmente.

This table si transports easily

'This table transports easily.'

(Cinque 1995, 170)

(4) La finestra si è aperta.

The window REFL is opened

'The window opened.'

(Centineo 1995, 54)

In their typological studies, Kemmer (1993) and Heine (2000) make the generalization that reflexive markers with an emphasis meaning are not used as markers for intransitive constructions. Conforming to this generalization, the Chinese reflexive marker ziji with an intensifying usage does not work as a pure marker for the above intransitive constructions. However, it can appear in anticausatives and express that no external force caused the change of state described, as in (5).

(5) Chuan ziji shen-le.

'By itself' reading

Boat ZIJI sink-PFV

'The boat sunk by itself.'

Such a reading is expressed by $x$-self in English, as shown in the English translation in (5), so it is named the 'by itself' reading, or equivalently the reading of 'without external cause'.

Furthermore, ziji also can express the other reading of English by $x$ self, namely the anti-group reading as in John went to Taipei by himself. This use of ziji is shown in (6), where ziji expresses that Zhangsan performed the action described, without anyone's accompaniment (cf. Tsai to appear for more examples of adverbial ziji).

${ }^{1}$ According to Keyser and Roeper (1984), the two constructions differ in that middles have a general reading, while anticausatives refer to a change of state resulting from some particular causing event. 
(6) A: What is Zhangsan doing?

B: Zhangsan ziji zai da dianwan. Anti-group reading

Zhangsan ZIJI progressive play video.game

'Zhangsan is playing video games alone.'

Many previous works, such as Levin \& Rappaport Hovav (1995) and Schäfer \& Vivanco (2016), have assumed that the two uses shown in (5) and (6) are two separate uses, between which no relationship exists. However, this assumption is dubious since crosslinguistically, the two meanings are often expressed by similar or identical expressions, for example, English by x-self, Chinese ziji and Italian da sé (cf. Schäfer 2007).

Another common but dubious assumption is that the intensifier meaning shown in (2) has nothing to do with the 'by itself' reading in anticausatives. Under this assumption, ziji in (2) and ziji in (5) are two different items. This assumption is probably made because the more well-studied languages do not use identical forms for the two uses, as demonstrated in (7).

(7) Expressions used for the "by itself" reading in anticausatives and the non-delegation reading (based on König \& Gast 2002; Hole 2005; Schäfer 2007; Constantinou 2014)

\begin{tabular}{lll}
\hline Language & $\begin{array}{l}\text { The 'by itself' reading in } \\
\text { anticausatives }\end{array}$ & $\begin{array}{l}\text { The non-delegation reading } \\
\text { (as an intensifier) }\end{array}$ \\
\hline Italian & da sé & stesso/-a \\
German & von selbst & selbst \\
English & by $x$-self (for inanimates) & $x$-self \\
\hline
\end{tabular}

Nevertheless, it is uncertain if the two uses are indeed unrelated in any way. Consider the following. First, German von selbst used for the causationrelated reading and selbst used for the non-delegation reading differ only in the presence of the preposition von. Second, crosslinguistically Chinese ziji is not the only item which can convey the two readings. The Hungarian reflexive marker maga 'self' can express all the readings available for Chinese adverbial ziji, as (8)-(11) demonstrate (Tamás Halm, personal communication).

(8) A fiú meg-ütötte magá-t. $\quad$ Reflexive anaphor the boy VERBAL.PARTICLE-hit.PAST self-ACC

'The boy hit himself.' (After accidentally falling, the boy hit himself on the curb.) 
(9) A fiú maga adta fel

a levelet.

Reflexive intensifier

the boy self gave VERBAL.PARTICLE the letter-ACC

'The boy posted the letter himself.'

(10) A virág magá-tól nyílt ki.

'By itself' reading

the flower self-from opened VERBAL.PARTICLE

'The flower bloomed by itself.'

(11) A fiú magá-ban eszik.

the boy self-in eats

'The boy is eating alone.'

Anti-group reading

As (8) shows, maga 'self' is a reflexive anaphor in Hungarian. In addition, it can also work as a verbal modifier, as shown by (9)-(11). It can take the unmarked nominative case and function as an intensifier to express the non-delegation reading, as in (9). It can also take the ablative case to express the 'by itself' reading (as in (10)), or take the inessive case to convey the anti-group reading (as in (11)).

This striking semantic similarity between Chinese ziji and Hungarian maga suggests that the different readings do not arise from lexical ambiguity of ziji or maga. Instead, the various surface meanings must derive from the same core semantics. For these reasons, a unified semantics of ziji will be pursued in this paper, and the various surface readings of $z i j i$-sentences will be argued to result from the interactions between syntax and domain variation.

The paper is organized as follows. In section 2, two previous analyses of adverbial ziji are discussed, with their weaknesses specified. In section 3, a new analysis of $z i j i$ is proposed: an adjunction-based syntactic analysis of ziji is presented in section 3.1, followed by a unified semantic function of ziji in section 3.2. Then, a step-by-step derivation of the three exclusive readings is shown in section 3.3, which reveals that the final interpretations of $z i j i$-sentences are affected by domain variation and the syntactic position of ziji. In section 3.4, the current proposal is further clarified with respect to the causation-related reading as well as the projection of CauseP. Then section 4 examines reading restrictions of ziji-sentences. The reading availability of ziji-sentences will be claimed to be affected by a relation presupposition triggered by ziji, while the reading restrictions shown in anticausatives will be inferred to arise from the necessary projection of CauseP. Finally, section 5 summarizes and presents the implications of the proposal. 


\section{Previous analyses of Chinese adverbial ziji}

\subsection{The focus analysis of ziji in Hole (2008)}

In the literature, there are two main analyses of Chinese adverbial ziji, the first of which to be discussed comes from Hole (2008). Hole's analysis is based on a focus analysis offered for English and German intensifiers, namely adverbial $x$-self and selbst, respectively. With obligatory stress on them, these intensifiers are believed to be involved with focus in previous works including Edmondson \& Plank (1978); König (1991; 2001); Siemund (2000); Eckardt (2001); Hole (2002); Gast (2002), among others.

Among these previous works, Hole (2008) in particular relies on Eckardt (2001) and Hole (2002) to develop an analysis of the Chinese adverbial ziji. Eckardt's (2001) analysis differs from previous works like König $(1991 ; 2001)$ and Siemund (2000) in that it does not treat an intensifier as a focus particle. A focus particle, like only or even, is associated with some focused item in its sentence, and operates over a set of alternatives evoked by the focus item. For example, the focus particle even requires that the associated focus item rank lowest among a set of alternatives in a likelihood scale for the predicate in question. In contrast with the focus particle analysis, Eckardt (2001) treats the German intensifier selbst as a focused item for reasons such as its obligatory stress. She then adopts Rooth's $(1985 ; 1992)$ two-dimensional semantics for focus, which is briefly introduced below.

In Rooth's theory, every expression has an ordinary semantic value as well as a focus semantic value. When an item is not focused, the two values of this item are the same. But if an item is focused, it will have two different semantic values. Take (12a) as an example.

(12) a. JOHN left.

b. $\quad\left\|[\operatorname{John}]_{\mathrm{F}} \operatorname{left}\right\|^{o}=\|\operatorname{left}\| \|^{o}\left(\left\|[\operatorname{John}]_{\mathrm{F}}\right\|^{o}\right)=\lambda e[\operatorname{left}(e) \wedge \operatorname{Agent}(e, \operatorname{John})]$

c. $\quad \|[\text { John }]_{\mathrm{F}}$ left ||$^{f}=\|$ left ||$^{f}\left(\left\|[\mathrm{John}]_{\mathrm{F}}\right\|^{f}\right)=\|$ left $\|^{o}\left(\left\|[\mathrm{John}]_{\mathrm{F}}\right\|^{f}\right)=\lambda x \lambda e[\operatorname{left}(e) \wedge$ $\operatorname{Agent}(e, x)]\left(\|\left[\mathrm{John}_{\mathrm{F}} \|^{f}\right)\right.$

d. $\left\|[\mathrm{John}]_{\mathrm{F}}\right\|^{f}=\left\{x: x \in D_{e}\right\}=\{$ John, Bill, Jane, ... $\}$

e. $\{\lambda e[\operatorname{left}(e) \wedge \operatorname{Agent}(e, \operatorname{John})], \lambda e[\operatorname{left}(e) \wedge \operatorname{Agent}(e, \operatorname{Bill})], \lambda e[\operatorname{left}(e) \wedge$ $\operatorname{Agent}(e$, Jane $)], \ldots\}$

The ordinary meaning of this sentence is presented in (12b), where $\|\mathrm{x}\|^{o}$ derives the ordinary semantic value of $x$. In addition to this ordinary semantic value, (12a) has a focus semantic value, shown in (12c). Left in 
(12c) is not focused, so its focus semantic value is the same as its ordinary semantic value, i.e., $\|$ left $\left\|^{f}=\right\|$ left $\|^{o}$. In contrast, John is focused. This item thus carries a focus feature, marked as $\mathrm{John}_{F}$, and has a set of individuals as its focus semantic value, shown in (12d). Then semantic composition is done in a pointwise way, with each individual in the set combining with the function denoted by left. This computation results in a set of sets of leaving events with various people as the agents, shown in (12e) as the focus semantic value of the whole sentence. Lastly, the final meaning of (12a) is gotten when the two dimensions of semantics are considered together: there is an event of John's leaving, but not an event of leaving by any other alternative agents in (12e). So it is derived that John, not any other person, left. Or to derive this meaning in a more syntactic way, one may assume that a covert only-like operator is applied to make the event to be the one described in (12b), but not the other sorts described in (12e) (cf. Chierchia et al. 2012 for covert exhaustivity).

Eckardt (2001) treats the German adnominal intensifier selbst as a focus item under Rooth's theory. As a focus item, its ordinary semantic value is different from its focus semantic value. The ordinary semantics value, based on Moravcsik (1972), is claimed to be an identity function, ID, shown in (13). To illustrate, I provide an English example in (14), as analyses of German intensifiers have often been applied to English intensifier $x$-self (cf. Constantinou 2014). In (14), the adnominal intensifier himself takes the entity John and returns to us the same individual. While the ordinary semantics adds nothing to the sentence's meaning, alternatives to the identity function are triggered, and the triggering elicits the consideration of alternative functions as illustrated in (15). As shown, the alternative functions include functions like the assistant-of function or the colleague-of function to get the associate's assistant or colleague. Therefore, a set of alternative individuals are considered, as in (15). After excluding the alternatives, (16) expresses that the letter-sending event was done by John instead of by Bill, by Jane, or by any other contextually relevant person.

(13) ID: $D_{e} \rightarrow D_{e}$

$\operatorname{ID}(a)=a$ for all $a \in D_{e}$

(Eckardt 2001, 377)

(14) $\|$ John $[\text { himself }]_{\mathrm{F}}\left\|^{o}=\right\|[\text { himself }]_{\mathrm{F}}\left\|^{o}\left(\|\mathrm{John}\|^{o}\right)=\right\|$ John $\|^{o}=$ John

(15) $\|$ John $[\text { himself }]_{\mathrm{F}}\left\|^{f}=\right\|[\text { himself }]_{\mathrm{F}} \|^{f}\left(\|\mathrm{John}\|^{f}\right)=\{$ Assistant-of(John), Colleagueof(John $), \ldots\}=\{$ Bill, Jane, ... $\}$

(16) John himself sent the letter to the company.

Acta Linguistica Academica 65, 2018 
As for adverbial intensifiers, unfortunately Eckardt assigns a very different semantics for adverbial selbst, namely (17), in deriving the "without assistance' reading in (18).

(17) $\left[\left[\right.\right.$ selbst $\left.\left._{\text {assistive }}\right]\right]=\lambda e \neg \exists x(\operatorname{ASSIST}(x, e))$

(18) Adrian fand den Weg zum Bahnhof SELBST.

Adrian found the way to-the station himself

Eckardt's treatment of adverbial intensifier selbst is surely not satisfactory. One obvious problem pointed out by Hole (2002) is that the adverb selbst is always stressed, but the semantic function in (17) does not involve focus. To solve this problem, Hole (2002) pioneers a proposal of a unified focus analysis of adverb selbst for its different surface readings. The proposed semantics is similar to Eckardt's proposal in the adoption of an identity function and alternative evocation. This analysis is extended to the Chinese adverbial ziji in Hole (2008), meaning that Hole treats adverbial ziji as an intensifier, like German and English intensifiers selbst and $x$-self. ${ }^{2}$

To be more specific, Hole (2008) argues that the intensifier ziji adjoins to the Voice head, which denotes the agent function (cf. Kratzer 1996), as in (19).

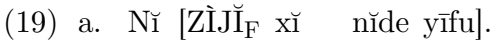

(Hole 2008, 283)

you SELF wash your clothes

'You wash your clothes YOURSELF.'

b.

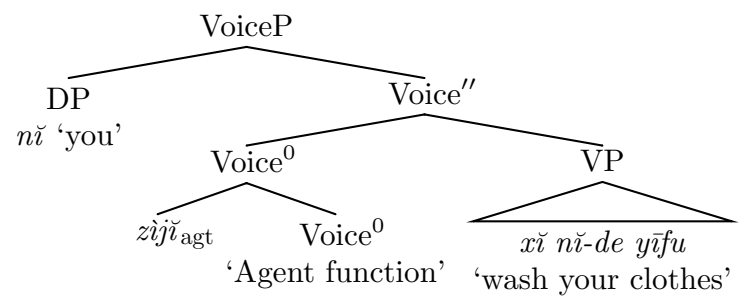

(ibid., 282)

As for its semantics, ziji as a focus item carries a focus feature and has an ordinary semantic value different from its focus semantic value. It is proposed that ziji denotes an identity function as its ordinary semantic value. Therefore, the meaning of the higher Voice ${ }^{0}$ should also denote the

${ }^{2}$ Previous works like Tang (1989) and Pan (1997) also take the Chinese adverbial ziji as an intensifier. Note that Chinese does not always have obvious phonological realization for expressions which should carry focus features in the focus theory. Thus, although ziji is not always stressed, it is possible to treat it as a focus item. 
agent function. The head Voice $^{0}$ combines with the VP and then with the subject NP to express that the entity denoted by the subject NP is the agent of the event denoted by the VP. In other words, ziji by its original semantic meaning simply keeps the sentence's original meaning. Crucially, $z i j i$ invokes the consideration of other thematic involvement of the subject NP, as shown in (20), where the subject NP might work instead as a causer or an assistant for the event.

(20) $\left[\mid z i j i_{F} \text { Voice }^{0} \|\right]^{f}=\{$ involvement of someone in an event, causative involvement of someone in an event, assisted involvement of someone in an event, ...\} (Hole 2008, 282)

As these alternative thematic relations do not hold, the final imperative meaning of $(19 \mathrm{a})$ is that you wash your clothes, rather than ask any other person in the context to do it for you.

Hole's analysis derives the desirable semantics for the non-delegation reading of ziji, and under some syntactic and semantic revision, it might also be able to derive the anti-group reading shown in sentence (6). However, this analysis has at least two shortcomings. First, seemingly a lot of alternative thematic functions should be added in the mechanism in order to derive the various surface readings of ziji. For example, in addition to the various thematic functions shown in (20), another thematic function is necessary for (21). (21) expresses that John went to Taipei without anyone's accompaniment. If Hole's mechanism is used to derive this meaning, there should be a thematic role like 'being accompanied by someone in an event', and (21) gets the meaning that John took the agent role but not the 'being accompanied role' for the event. It is doubtful whether so many semantics roles exist in the language faculty.

(21) John ziji qu-le Taipei.

John ZIJI go-PFV Taipei

'John went to Taipei by himself.'

Second, note also that Hole intentionally associates the intensifier ziji to the agent function because he has assumed an agentivity constraint for the use of adverbial intensifiers (cf. Hole 2002). However, as will be discussed in Section 4.1, there are several counterexamples to this constraint. So the association of ziji with the agent function is not advantageous. On the contrary, this association makes it harder to propose a unified semantics for adverbial ziji. To see this, consider sentence (5). In (5), the associate of $z i j i$ is inanimate and cannot function as an agent for the sinking event. It is difficult to apply Hole's analysis to this use of ziji. Therefore some other analysis must be provided if only one ziji is assumed. 


\subsection{The inner-outer dichotomy of ziji in Tsai (2015; to appear)}

Another important previous analysis of adverbial ziji is seen in Tsai (2015; to appear). Tsai (to appear) provides rich data for adverbial ziji and highlights the three different readings of ziji. Crucially, he argues for an innerouter dichotomy of ziji, based on the correlation between this word's meanings and its syntactic positions relative to modal words, negation words, adverbs of quantification, and control verbs. The correlation is as follows. Before these elements, ziji works as an outer Self operator. It is located higher in the syntactic structure and contributes a causation-related meaning. In contrast, when ziji follows these elements, it is located lower in the structure as an inner Self operator, contributing an 'in person' reading (= the non-delegation reading illustrated by sentence (2)) or an alone-like reading (= the anti-group reading illustrated by example (6)). A concrete example borrowed from Tsai (to appear) is seen in (22) with slight modification for ease of discussion.

(22) a. Tamen ziji yinggai chuli zhe-jian shi.

they self should handle this-CL matter

'They should handle this matter on their own initiative.'

b. Tamen yinggai ziji chuli zhe-jian shi.

they should self handle this-CL matter

'They should handle this matter in person.'

(Tsai to appear, 3)

The two sentences in (22) differ in ziji's position relative to the modal word yinggai 'should'. The pre-modal ziji in (22a) gets the meaning of 'on one's own initiative' (i.e., the causation-related reading), whereas the post-modal ziji in $(22 \mathrm{~b})$ has the 'in person' reading.

The inner-outer dichotomy revealed by ziji is argued to reflect the distinction of two peripheries, the vP periphery (cf. Belletti 2004; 2005) and the left periphery (cf. Rizzi 1997). Inner Self merges to the edge of the vP periphery by adjoining to $\mathrm{vP}$ (as in Tsai 2015) or in the specifier position of FocP which is right above vP (as in Tsai to appear). In contrast, outer Self merges to the CP/IP layer in the left periphery, located in the specifier position of CauP or a higher FocP (see Tsai (2015; to appear) for the various possibilities). The inner-outer dichotomy is visualized in the diagram in (23) (based on Tsai to appear, 10), which displays the places of inner Self and outer Self and shows the places of ziji for its two other reflexive uses, namely the uses of logophoric Self in [Spec, SrcP] (based on Huang \& Liu 2001) and anaphoric Self inside VP. Having presented a complete analysis of $z i j i$, Tsai (to appear) concludes that ziji in its various uses sup- 
ports the cartographic theory advocated in Rizzi (1997) and Cinque (1999) that there is rigid universal ordering of functional projections in the left periphery, each licensing a small class of adverbs to locate in its Specifier position.

(23) ${ }_{\mathrm{SrcP}}$ logophoric Self $\left[_{\mathrm{Src}^{\prime}} \cdots\left[_{\mathrm{FocP}}\right.\right.$ outer Self $\left[_{\mathrm{Foc}^{\prime}}\right.$ Foc $\left[_{\mathrm{ModP}} \ldots\left[_{\mathrm{FocP}}\right.\right.$ inner Self $\left[\right.$ Foc $^{\prime}$ Foc ${ }_{\mathrm{vP}}\left[\mathrm{v}^{\prime} \mathrm{v}[\mathrm{vP} \mathrm{V}\right.$ anaphoric Self]]]]]]]]]]

As for the semantics of inner Self and outer Self, Tsai claims that adverbial ziji works to establish a coargument relation, just like a reflexive anaphor does. Specifically, inner Self at the edge of vP associates the subject with a comitative argument, and outer Self at the IP/CP layer presupposes an implicit causative predicate and associates the subject with the causer argument of this predicate. In addition to co-argument establishment, ziji in Tsai's analysis also evokes other possible alternatives to the comitative/ causer argument, just like in Hole's (2008) analysis. In cases where the comitative argument must be identical with the subject referent rather than the other possible alternatives, an alone-like reading is derived, as represented in (24b) for (24a); and in cases where the causer argument is identical to the subject referent but not the other possible alternatives, the 'on one's own initiative' meaning is gotten, as represented in (25b) for $(25 \mathrm{a})$.

(24) a. Akiu ziji chuli-guo zhe-jian shi.

Akiu self handle-Past this-CL matter

'Akiu handled this matter by himself before.'

b. $\exists e($ handling $(e)$ \& Agent $($ Akiu, $e)$ \& Theme (this matter, $e) \&$

Comitant $(A k i u, e) \& \sim \exists y(y \neq A k i u \&$ Comitant $(y, e)))$ (Tsai to appear, 14-15)

(25) a. Akiu ziji hui chuli zhe-jian shi.

Akiu self will handle this-CL matter

'Akiu will handle this matter on his own initiative.'

b. $\exists e(\operatorname{CAUSE}($ Akiu, e) \& handling $(e) \&$ Agent $($ Akiu, e) \&

Theme (this matter, $e) \& \sim \exists y(y \neq$ Akiu \& CAUSE $(y, e))$

(ibid., 20)

In addition to the anticausative reading presented in (25b), Tsai also identifies two other causation-related meanings, which are derived when outer Self merges to a very high position, scoping over the entire IP and thus having no way to establish a co-argument relation for the subject. Two of the examples given in Tsai (to appear) are presented in (26)-(27) below. 
(26) a. Feng da-le, men ziji hui kai.

wind big-INC door self will open

'When wind grows stronger, the door naturally will open.'

b. $\lambda e \exists e^{\prime}$ (CAUSE $\left(e, e^{\prime}\right)$ \& opening $\left(e^{\prime}\right) \&$ Theme (the door, $\left.\left.e^{\prime}\right)\right)($ stronger wind)

(Tsai to appear, 19)

(27) a. Bu zhi zenme de, Akiu ziji ku-le qilai.

not know how DE Akiu self cry-INC up

'(I) don't know how (that happened). Akiu started to cry without cause.'

b. $\exists e^{\prime}\left(\sim \exists e\left(\operatorname{CAUSE}\left(e, e^{\prime}\right)\right) \&\right.$ crying $\left(e^{\prime}\right) \& \operatorname{Sentient}\left(\right.$ Akiu, $\left.\left.e^{\prime}\right)\right)$

(ibid., 20)

In the two examples, ziji 'essentially serves as a $\lambda$-operator binding a predication variable introduced by the cause event' (19). In (26), the cause is identified in the context as the strong wind; and in (27), the lack of any cause in the context results in the 'without cause' reading for this sentence.

Tsai's detailed examination of ziji's various readings in different sentences serves as the foundation of the current research. Through his findings, the current paper identifies the three main readings of adverbial $z i j i$, namely the anti-group reading, the non-delegation reading, and the causation-related reading. Moreover, it aims to derive the same final meanings for the alone-like reading (such as (24)) and for the causation-related reading (such as (25)). Nevertheless, eventually it has to provide another analysis for ziji because Tsai's analysis faces both semantic and syntactic challenges as shown below.

Tsai's analysis makes it doubtful whether a unified semantics of ziji for all the exclusive uses can be achieved. First, it is unclear how inner Self derives the 'in person'/non-delegation reading in sentences like (2). Under this reading, ziji evokes the consideration of various possible agents for the event in question, such as the consideration of \{Bill sent the letter, Joh sent the letter $\}$ for (2). Inner Self, which is claimed to relate to a comitative argument, cannot result in the consideration of such alternatives. Consequently, some other function must be proposed for ziji, resulting in multiple functions for adverbial $z i j i .^{3}$

Tsai even explicitly shows two different functions of adverbial ziji in his analysis. That is, ziji shift its semantic function in (26) and (27) from a function involving with co-argument and focus to another entirely different function related to a $\lambda$-operator which binds an event variable. Even though it is not impossible that some item could shift its semantic function

${ }^{3}$ In her thesis, Liao (2017) also points out this as a problem of Tsai's (to appear) analysis of ziji. 
by context or because of some semantic incompatibility, such a proposal must be independently supported and the mechanism must be clarified. Besides, this mechanism must also be universal in order to account for the various uses of Chinese ziji as well as the Hungarian reflexive marker maga.

In addition to the above semantic concerns, Tsai's analysis encounters syntactic challenges, too. While it is undeniable that Tsai's inner-outer dichotomy and the overall analysis of Self operators in the cartographic approach are very attractive, there are counterexamples for the dichotomy, as shown below.

First, it is claimed that a causation-related reading is derived by outer Self in a very high position; however, there are cases where ziji in a relatively low position elicits this reading. To show this, we can apply the test used in Schäfer (2007). Schäfer makes (28a) and (29a) followed by sentences expressing that no one else has also taken part in the event (such as (28b)) or that no one has caused the event to take place (such as (28c)). As (28a) can be followed by (28c) but not (28b), Schäfer concludes that von selbst can have the anti-causative meaning but not the alone-like meaning. Under the same test, he concludes that allein has the alone-like meaning only.

(28) a. Hans hat die Vase von selbst zerbrochen.

Hans has the vase by self broken

b. "Niemand hat mitgemacht.

nobody has with-made/taken part

c. Niemand/nichts hat ihn dazu veranlasst.

nobody/nothing has him this-to caused

(29) a. Hans hat die Vase allein zerbrochen.

Hans has the vase alone broken

b. Niemand hat mitgemacht. nobody has with-made/taken part

c. ${ }^{\#}$ Niemand/nichts hat ihn dazu veranlasst. ((28)-(29) from Schäfer 2007, 6-7) nobody/nothing has him this-to caused

Schäfer's test can be applied to (30)-(32). In all these examples, the zijiclauses can be followed or preceded by a statement about causation. Thus, all these clauses express causation-related meanings. 
(30) Xiaoming changchang ziji xie zuoye, bu-yong mama qiangpo.

Xiaoming often ZIJI write assignment not-use mother force

'Xiaoming often writes assignments on his own initiative, without being forced by his mother.'

(31) Xiaoming mei ziji xie zuoye,

Xiaoming not ZIJI write assignment

shi mama qiangpo cai xie de.

be mother force CAI write DE

'Xiaoming didn't write the assignment on his own initiative. He was forced by his mother to write it.'

(32) Bu-yong da pigu, xiao baobao hui ziji ku.

not-use hit bottom little baby will zIJI cry

'There is no need to spank it. The infant will cry by itself.'

The intuition is made more evident when zhudong 'on one's own initiative', yi-ge-ren 'alone', or qinzi 'in person' is used to replace ziji. In all the sentences, zhudong but not yi-ge-ren or qinzi is a good substitute for ziji, following the intuition that ziji has a causation-related meaning instead of the alone-like or the 'in person' meaning in these sentences. ${ }^{4}$ Note that ziji follows an adverb of frequency, a negation morpheme, and a modal word in (30), (31), and (32), respectively. So the data here show that even in a low position, ziji may bring in a causation-related reading. ${ }^{5}$

${ }^{4}$ For cases like (30)-(32), a reviewer wondered whether the 'in person'/non-delegation reading could be viewed as the reading brought out by lower ziji, and whether the causation-related reading could be taken as an implicature, an inferred reading. At first, this analysis seems possible, since in any of the examples in (30)-(32), the associate of ziji is the one to conduct the action(s) denoted. For instance, in (30) Xiaoming is the one to write assignments, and thus Xiaoming does it 'in person'. But does this mean that the 'in person'/non-delegation reading is conveyed by (30)? It is unlikely. In the current analysis, (30) expresses that Xiaoming causes himself to do the assignment-writing activities. When this holds, Xiaoming is surely the agent (or at least one of the agents) of the activities. Nevertheless, the establishment of agency does not mean that the so-called non-delegation reading is expressed. Otherwise, it is unclear why qinzi 'in person' cannot be used as a substitute for ziji to unambiguously express the non-delegation meaning for (30)-(32). Based on this, I conclude that the causation-related reading but not the non-delegation reading is conveyed by ziji in (30)-(32).

${ }^{5}$ Interestingly, according to two Mandarin native speakers, if the clause er bu shi bieren qiangpo cai zuo 'but not be other people force CAI do = not do it because being forced by other people' is added to follow Tsai's examples in (22), (22b) sounds better than (22a). This shows that (22b) can have a causation-related reading, contra to Tsai's intuition. In fact, it is indeed hard to judge what meanings adverbial ziji expresses in 
There are also examples showing that ziji in a high position may derive the 'in person'/non-delegation reading. Look at (33)-(35). Every question in these examples asks who should hold for its predicate, so the answer expresses something like that A instead of B holds for the statement. This is the so-called non-delegation reading. With some context information added for each example, all the ziji-sentences are proper answers to express the non-delegation reading, even though ziji precedes an adverb of quantification, a negation morpheme, and a modal word in (33), (34), and (35) respectively.

(33) A: Shei changchang qi zhe mian qiang?

who often paint this CLF wall

'Who often paints this wall?'

(contextual knowledge: this wall referred to is in Zhangsan's house)

B: Zhangsan ziji changchang qi zhe mian qiang.

Zhangsan ZIJI often paint this CLF wall

'Zhangsan often paints this wall himself.'

(34) A: Shei mei juan qian?

who not donate money

'Who didn't donate money?'

B: Zhangsan ziji mei juan qian.

Zhangsan ZIJI not donate money

'Zhangsan himself didn't donate money.'

(contextual knowledge: Zhangsan was the one who asked everyone to donate money)

(35) A: Shei hui chuli zhe jian shi?

who will handle this CLF matter

'Who will handle this matter?'

B: Akiu ziji hui chuli zhe-jian shi. $\quad((35 \mathrm{~B})=(25 \mathrm{a}))$

Akiu self will handle this-CL matter

'Akiu will handle this matter on his own initiative.'

(contextual knowledge: the subject in $(35 \mathrm{~B})$ is responsible

for the matter in question)

several sentences in Tsai's papers. Several Mandarin native speakers whom I consulted have hesitated to make a decision on the meanings contributed by ziji. This reaction however may be reflecting the paper's claim in Section 3 that the meaning of exclusive ziji is determined partly by context, and so when people have different contexts in mind, they may have different intuition about ziji-sentences. 
It should be made clear that the non-delegation reading for (33)-(35) is not an inferred reading, nor is it an additional reading on top of the causationrelated reading. In these examples, self-causation is not expressed and not in the truth conditions of these ziji-sentences. To see this, let us take (34) as an example. B's response in (34) can be followed by the utterance 'But Zhangsan didn't intend to do such a bad thing. His wife ordered him not to donate any money'. The possibility of this continuation reveals that B's response in (34) does not have self-causation in its truth conditions. Otherwise, the continuance should encounter a semantic conflict, contra to fact. Therefore, what ziji contributes to (34) is not a causation-related reading, but a non-delegation reading. The same reasoning can be applied to (33) and (35).

It should be further noted that all the answers in (33)-(35) may also express the alone-like/anti-group reading, if some additional contextual knowledge is added. For example, if it is common knowledge for (33) that Zhansgan usually redecorates his house with his elder brother or his younger brother, (33B) can express the following anti-group reading: it is often the case that Zhangsan paints this wall without his brothers' help.

In short, the examples in (30)-(35) show that ziji may express all three readings, regardless of whether it is located in a relatively high or low position. ${ }^{6}$ The fact that Tsai's (2015; to appear) inner-outer dichotomy of ziji is empirically correct to some extent is arguably due to the semantic effects of how ziji interacts with the elements it combines with in different syntactic positions. Moreover, the fact that some readings may not be gotten in some sentences is due to the effects of context and predicates on the reading availability of ziji-sentences. This will be made clearer later in the paper.

In this section, two important previous analyses of adverbial ziji are discussed and their shortcomings are identified. In the next section I will revise their analyses to make a new proposal which can assign adverbial $z i j i$ a unified semantic function for the three readings indicated and which can more completely account for the empirical facts.

${ }^{6}$ Tsai (2015; to appear) also uses control verbs to test the syntax-semantics correlation for ziji. However, since sentences with control verbs are more complex, the current paper will focus on simplex sentences at this stage, and complex cases like (i), which was raised by one anonymous reviewer, will be discussed in footnote 12 .

(i) Mama qiangpo Xiaoming (*ziji) yao (ziji) xie zuoye. mother force Xiaoming self YAO self write homework 'Mother forced Xiaoming to do homework (by himself).' 


\section{A new analysis of Chinese exclusive ziji}

\subsection{An adjunction-based structure of adverbial ziji}

The first step of my analysis is to consider how to deal with the causationrelated reading. To derive such a reading, some causation-related element must appear in the syntactic structure of $z i j i$-sentences, like the projection of CauP proposed in Tsai (2015) or the presence of an implicit causative predicate in some place close to adverbial ziji as suggested in Tsai (to appear). It should be clarified, though, that this causation-related element is for internal causation only. Internal causation differs from external causation. The two types of causation are distinguished in Levin \& Rappaport Hovav (1995). While verbs like break can take an external argument to express the external cause of the eventuality referred to (as in John broke the window), verbs like speak, play, and blush describe internally caused eventualities, and the causes for such eventualities are volition or some internal properties of the subject NPs. For example, John's volition is the internal cause for the eventuality of John spoke to Mary. How external causation and internal causation should be treated differently and in what ways they may work similarly are complicated and controversial issues. Although the current paper attempts to explore a possible mechanism working for internal causation via the study of ziji, it does not address how to treat the two sorts of causation differently in syntax. ${ }^{7}$ However, based on the empirical facts shown in the previous section, the following can be inferred: the causation-related element (at least for internal causation) should be able to appear in a relatively high or low position, as the causation-related reading is observed in both positions.

In addition to the causation-related reading, the readings of the socalled inner Self are not so restricted by the syntactic position of ziji either. I then propose the following structure for ziji, based on the assumption that there is only one adverbial ziji:

(36) $\ldots$

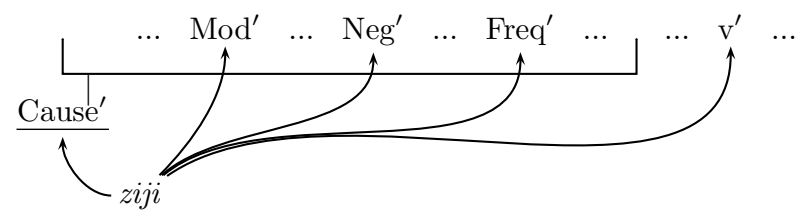

${ }^{7}$ Interested readers are referred to papers about internal causation, such as Pylkkänen (1999; 2002; 2008); Nelson (2000); Markman (2003); Grahek (2009), and the many other previous studies which discuss by itself in English or corresponding expressions in other languages, like Chierchia (2004) and Rákosi (2012). 
(36) represents the idea that CauP (or more conservatively and precisely $\left.\mathrm{CauP}_{\text {internal }}\right)$ can be projected in a high or low position, and in the structure the adverbial ziji has the flexibility for its adjunction position: it adjoins to some $\mathrm{X}^{\prime}$ node, and this node can be Cause', $\mathrm{Mod}^{\prime}, \mathrm{Neg}^{\prime}$, Freq', or v'. Among the different adjunction positions, a causation-related reading is derived when ziji targets Cause' for adjunction and evokes other possible causers for the event in question. If instead ziji adjuncts to other nodes, it will simply evoke alternatives to the subject referent and derive the anti-group or the non-delegation reading. As to be shown in the next subsection, this syntactic proposal will not only account for the empirical facts in a better way, but it will also give us a simple semantic analysis of adverbial ziji.

The syntactic analysis of adverbial ziji I have proposed, in fact, fits more with the 'adjunction theory' of adverbs in works like Ernst (2002); Haider (2004) and Nilsen (2004) than the cartographic theory advocated in Rizzi (1997) and Cinque (1999) and supported in Tsai (to appear). The crucial difference between these two approaches, as Ernst (2014) points out, is as follows. The cartographic theory assumes that adverbials are in the specifier positions of a set of function projections which are arranged in a strict order, but the adjunction theory assumes that adverbials adjoin to maximal projections or $\mathrm{X}^{\prime}$ nodes, and their adjoining positions are not so regulated in syntax. In the latter theory, some semantic rules or semantic composition will determine whether some adjunction can be done. If there is no rule violation in semantics or no semantic clash, the adjunction is allowed. It is obvious that the diagram shown in (36) fits better with the adjunction view, as there are many adjunction possibilities for adverbial ziji.

Furthermore, as shown in Ernst (2014), different adjunction positions of adverbials interact with other elements in the sentences in different ways, and may affect the sentences' meanings, illustrated by (37a) and (37b).

(37) a. Zhangsan zhi (shi) ou'er qu canjia taolunhui.

Zhangsan only be occasionally go attend discussion

'Zhangsan only attends the discussion occasionally.'

b. Zhangsan ou'er zhi qu canjia taolunhui.

Zhangsan occasionally only go attend discussion

'Zhangsan occasionally only attends the discussion.'

(Ernst 2014, 59)

In Section 3.3, I will argue that the same holds true for adverbial ziji. ${ }^{8}$

${ }^{8}$ The paper will examine a concrete example in footnote 12 to show how under the current analysis, the interaction of ziji and the elements it combines with may result 


\subsection{A unified semantics of exclusive ziji}

\subsubsection{The structure of anticausatives}

Before I show the step-by-step derivation for the various readings of $z i j i$, it is important to go back to (26a), one of Tsai's causation-related examples, repeated below.

$\left(26^{\prime}\right)$ Feng da-le, men ziji hui kai. wind big-INC door self will open

'When wind grows stronger, the door naturally will open.'

As mentioned above, Tsai claims that this sentence with the 'by nature' reading does not involve alternative semantics, and he makes this use of ziji quite different from its uses in the anticausative reading or in the alone-like reading. But in contrast with this claim, it is actually possible to retain a focus analysis for all uses of adverbial ziji, including the use in (26a). To see this, let us discuss the structure of anticausatives.

An important issue in the study of causation is the alternation between the transitive use and intransitive use of some verbs like sank in (38a-b). Sank can have a transitive use, as in (38a), where the external argument the enemy is the causer to make the internal argument the boat to sink. Sank also can take only one argument, as in (38b), which describes the change of state of this sole argument. In the intransitive use, the causer of the change of state is not identified, and thus such sentences are often called anticausatives in the literature.

(38) a. The enemy sank the boat.

b. The boat sank.

Two analyses have been proposed for the structure of anticausatives. On the one hand, as anticausatives do not take overt NPs as causers, a more traditional analysis is that anticausatives contain no causation information at any conceptual representation or in any syntactic structure. Support for this analysis is given by Lakoff (1968; 1970); Dowty (1979); Williams (1981); Parsons (1990); Hale \& Keyser (1993); Pesetsky (1995); Travis (2000); Ramchand (2008); Schäfer \& Vivanco (2016), and many others. According to this approach, the event decomposition for causative sentences such as (38a) involves a CAUSE event, a BECOME event, and a result state, but the event decomposition for anticausatives such as (38b) involves

in a semantic clash, so as to explain why ziji may fail to appear in some syntactic position or fail to get some surface meanings in some syntactic positions. 
only a BECOME event and a result state. In the syntactic structure, CauseP or any variant of such a projection is not projected.

On the other hand, works including Levin \& Rappaport Hovav (1995); Chierchia (2004); Kratzer (2005); Schäfer (2008); Koontz-Garboden (2009); Manzini \& Savoia (2001; 2011); Medová (2012); Beavers \& Koontz-Garboden (2013a; 2013b), among others, suggest that information about causation is present not only in causative sentences but also in anticausatives, where the cause component is claimed to be either at some level of semantic representation, in some syntactic feature, or by some causation-related maximal projection. For example, based on the event decomposition analysis proposed in Kratzer (2005) and Alexiadou et al. (2006a;b), (38a) and (38b) can be represented as in (39a) and (39b) respectively, where the only difference between them is the presence of the agent-introducing Voice.

(39) a. [the enemy [Voice [CAUSE [the boat SINK]]]]

b. [CAUSE [the boat SINK]]

That is, causatives and anticausatives differ in the presence of the agent, but do not differ in the coding of causation. Given this, the $\mathrm{v}_{\mathrm{CAUSE}} /$ Cause head and $\mathrm{vP}_{\text {CAUSE }} /$ CauseP are projected in both causatives and anticausative (cf. Schäfer 2008).

A further issue under the latter approach is about the nature of the causer. For this issue, adjuncts like Italian $d a$ sé and English by itself are often discussed. The occurrence of such adjuncts in anticausatives are claimed to express the lack of external force in some works, like Schäfer (2007); Horvath \& Siloni (2011; 2013); Alexiadou et al. (2015), and Schäfer \& Vivanco (2016). For example, (40) means that the boat sunk without external force.

(40) La barca è affondata da sé.

"The boat sunk by itself.'

(Cheirchia 2004, 43)

However, this is not agreed upon by all researchers. Chierchia (2004) and Koontz-Garboden (2009) argue for a reflexivization analysis of anticausatives. In such an analysis, a reflexivization operation is applied to make the causer identical to the theme which undergoes the change of state in an anticausative construction. Accordingly, (38b), for instance, has the meaning that the boat caused itself to sink. And Chierchia (2004) supports the reflexivization proposal by the use of Italian $d a$ sé 'by oneself'. Crucially, this adjunct can be used only when the subject NP is the sole agent or internal causer of the event described, as shown in (41a-b). 
(41) a. Gianni mi ha picchiato da sé.

'Gianni hit me by himself.'

b. *Gianni ha sudato da sé.

'Gianni sweat by himself.'

(Cheirchia 2004, 42)

As Gianni is the agent for the hitting event in (41a), da sé can be used; in contrast, since Gianni is not an agent in (41b) and cannot cause his own sweating, the use of $d a$ sé is unacceptable. Given this, from the grammaticality of (40) we can infer that la barca 'the boat' works as the causer in this sentence. As the boat was inanimate and could not act to make itself sink, it must have caused the sinking event via some of its internal properties, such as its density or heaviness. So, the resulting reading can be called 'the internal causation' reading.

Chierchia's internal causation analysis of anticausatives is crucial in the pursuit of a unified semantics for the Chinese adverbial ziji. Under the internal causation analysis, it will become clear that adverbial ziji expresses a similar meaning for all its different surface readings, as argued below.

\subsubsection{A unified exclusive meaning of $z i j i$}

To help the reader capture the essentials of my unified semantics of adverbial ziji, I will start this subsection by using (2) and (42) as examples to show how to distinguish two quite different uses of adverbial ziji, namely the exclusive use and the inclusive use.

Sentence $(2 \mathrm{~B})$, repeated below as $\left(2^{\prime} \mathrm{B}\right)$, expresses that the letter sending event was performed by John, not any other person.

$\left(2^{\prime}\right) \quad$ A: Did Bill send the letter for John?

B: Meiyou, John ziji ji-le xin.

No, John ZIJI send-PFv letter

'No, John sent the letter himself.'

As other people are excluded with respect to the predicate, the non-delegation reading has a sense of exclusion. Thus ziji is an exclusive intensifier in this case.

In contrast with (2), (42) conveys an inclusive meaning, since by (42), not only John but also some other person in the context has pens. With an inclusive meaning conveyed, ziji in this example works as an inclusive intensifier (cf. König 1991; 2001; König \& Siemund 2000; Siemund 2000, and Constantinou 2014 for the uses and properties of inclusive intensifiers). 
(42) John yinggai ziji you bi, bu-yong gei ta bi.

John should ZIJI have pen no-use give he pen

'John should have pens himself. You don't need to give him pens.'

In this paper, I aim to provide one unified semantics of exclusive ziji, while I will not provide any further comments on inclusive ziji. ${ }^{9}$ To do this, I will concentrate on the three readings of ziji examined in Tsai (2005; to appear), namely the non-delegation reading, the anti-group reading, and the 'by itself'/causation-related reading. Below I clarify that the three targeted readings are all uses of exclusive ziji, by demonstrating that the three readings all express some sense of exclusion.

First, let us represent the exclusive meaning of the non-delegation reading of $z i j i$ in (43a).

(43) Common properties of all the readings
a. Non-delegation reading
$\{$ John, $a, b, \ldots\}$
b. Anti-group reading
$\{$ John, $\uparrow($ Jøhn $\oplus a), \uparrow(J \odot h n a \oplus b), \ldots\}$
c. Internal causation reading
$\{$ The boat, the enemy, the general, ... $\}$

The exclusive meaning of ziji makes the other contextually relevant people, like $a, b, \ldots . .$. , not true for the predicate in question, visualized as the deletion of these individuals in (43a). Such a meaning is expressed in (2), which conveys that John, not the other contextually relevant people, sent the letter.

Next, consider the anti-group reading in sentence $(6 \mathrm{~B})$, repeated below as $\left(6^{\prime} \mathrm{B}\right)$.

${ }^{9}$ In fact, the previous works mentioned above have also identified another use of intensifiers, namely the adnominal use. Take the intensifier himself as an example. It has an adverbial use, as in John kicked the ball himself, and an adnominal use, as in John himself kicked the ball. Chinese ziji as an intensifier also has the two different uses. However, the adnominal uses of ziji are beyond the scope of this paper. In the rest of paper, any ziji-sentences presented and discussed will be sentences with adverbial ziji. These sentences are usually simple, so ziji is adjacent to the subject NPs, though it can be separated from these NPs by some adverbs. For example, the adverb zuihou 'at last' can be added to (2B), as shown below. The same holds for the other $z i j i$-sentences to be discussed. Thus, only the uses of adverbial ziji are examined in the paper.

(i) Meiyou, John zuihou ziji ji-le xin.

no John at last ZIJI send-PFV letter

'No, John sent the letter himself at last.' 
$\left(6^{\prime}\right)$ A: What is Zhangsan doing?

B: Zhangsan ziji zai da dianwan.

Zhangsan ZIJI progressive play video.game

'Zhangsan is playing video games alone.'

$\left(6^{\prime} \mathrm{B}\right)$ expresses that John is playing the game, without other people accompanying him. That is, John is not doing the activity with person a or with people $\mathrm{a}$ and $\mathrm{b}$, for instance. Therefore, the meaning can be represented as in (43b), where possible group entities like $\uparrow(\operatorname{John} \oplus a)$ (i.e., the group with the plural John and a) or $\uparrow($ John $\oplus a \oplus b)$ (i.e., the group with the plural John, a, and b) are made false for the predicate (cf. Link 1984; Landman 1989; 2000 for the use of group formation operator $\uparrow$ to turn plural entities into groups, such as the application of $\uparrow$ over the plural of John and a, represented as $\uparrow(\operatorname{John} \oplus a))$.

Finally, sentence (5), repeated below as an example for the causationrelated reading, is an anticausative.

$\left(5^{\prime}\right)$ Chuan ziji shen-le.

'By itself' reading

Boat ZIJI sink-PFV

'The boat sunk by itself.'

As discussed in Section 3.2.1, by Chierchia's internal causation analysis of anticausatives, the boat in $\left(5^{\prime}\right)$ is taken as an internal causer for its own sinking event. On top of this, it is often argued that this sentence expresses the sense of 'without external cause'. Interestingly, this is an exclusive meaning. That is, this sentence expresses that the boat is the causer, and other possible external forces, like some enemy or some general, are made false for the causer role of the sinking event, as visualized in (43c).

So far, it should be clear that the three readings of ziji are very similar semantically. Therefore it is possible and tempting to propose a unified semantics for the three uses of ziji. Moreover, if my analysis can show how $z i j i$ expresses the various exclusive meanings in a systematic way, it will in turn support the internal causation analysis in Chierchia (2004) and Koontz-Garboden (2009) for anticausatives.

\subsection{Deriving the three readings of exclusive ziji}

In this subsection, I will show step by step how the various readings of exclusive ziji are derived under a unified semantics of ziji. Crucially, I will demonstrate that it is domain variation and syntax that work together to derive the various surface readings. 
As I have argued, the Chinese adverbial ziji 'self' in its exclusive use has many adjoining possibilities, and the final meanings of its sentences are affected by whether it adjoins to Cause' or some other $\mathrm{X}^{\prime}$ node. To explain how ziji derives the three different readings, I will discuss the two adjoining possibilities shown in (44).

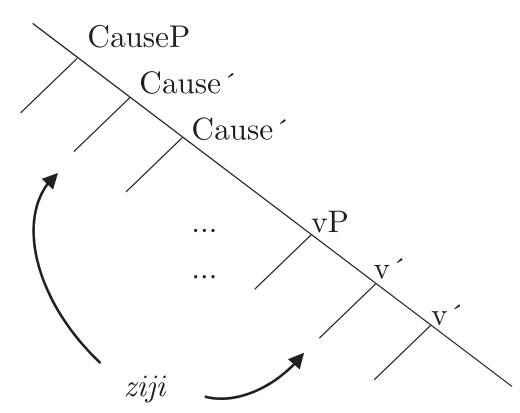

Like Hole (2008) and Tsai (to appear), I adopt Rooth's focus theory to derive the various meanings of ziji-sentences. In particular, I follow Hole (2008) in assuming that ziji is a focus item, instead of a focus particle like only or even. Specifically, under this assumption, ziji always carries a focus feature and has a focus semantic value different from its ordinary semantic value, so it evokes alternatives for consideration. For its ordinary semantics, I follow Hole (2008) again for the use of an identity function. The identity function is shown in (45a), where ziji takes some $P$ of type $\langle e,\langle\epsilon, t\rangle\rangle$, and returns to us $P$. As discussed above, as an identity function, this item does not add anything to the original semantic value of its sentence. But it contributes to the final meaning by its focus semantic value, which is displayed in (45b). By (45b), ziji triggers a set of functions such that each function in the set takes $P$ and returns to us $\lambda x[P(y)]$, which will take some entity $x$ as its argument but then make $\mathrm{P}$ true for some y instead of $x$, and as required in (45b), $y$ should be a contextually relevant entity.

(45) Semantics of Chinese exclusive ziji

a. $\left[\left|\mathrm{ziji}_{\mathrm{F}}\right|\right]^{o}=\lambda P: P \in D_{\langle e,\langle\epsilon, t\rangle\rangle} \cdot P \quad$ (First version)

( $\epsilon$ is the type for event entities)

b. $\quad\left[\left|z \mathrm{ziji}_{\mathrm{F}}\right|\right]^{f}=\left\{\lambda P: P \in D_{\langle e,\langle\epsilon, t\rangle\rangle} \cdot \lambda x[P(y)]: y \in D_{e / c}\right\}$

where $c$ stands for context, and $D_{e / c}$ is a domain for entities which are of type $\langle e\rangle$ and which are contextually relevant 
Now, let us use (46a) as a concrete example to illustrate how the syntactic assumption in (44) and the semantics in (45) together derive the non-delegation reading.

(46) a. John ziji ji-le xin. $^{10}$

John ZIJI send-PFV letter

'John sent the letter himself.'

b.

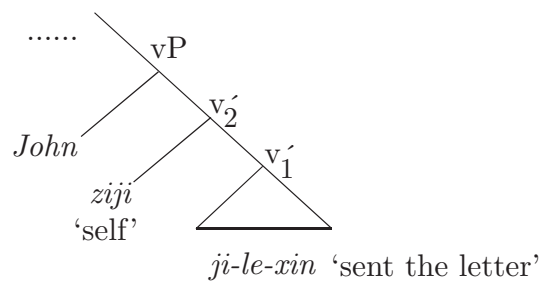

(46a), an example for the non-delegation reading, has the structure shown in (46b). As claimed, the ordinary semantic value of ziji is an identity function. Thus, the ordinary semantic value of $\mathrm{v}_{2}^{\prime}$ should be the same as that of $\mathrm{v}^{\prime}{ }_{1}$, which is a function taking the subject NP and then deriving the truth condition that the individual denoted by the subject NP is the agent for the event described. So, the sentence is true if and only if John acted as the agent for the letter-sending event.

As for the focus semantic value, as shown in (47), ziji will take the function denoted by $\mathrm{v}^{\prime}{ }_{1}$ as its argument, and then returns to us a set of functions such that each function in the set will take the subject NP as its argument but eventually make some $y$, some contextually relevant person, be the agent of the letter sending event. Then, a set of alternative propositions is derived, as in (48). After the subsequent application of a covert only-like operator, (46a) will get the meaning that John but not any other contextually relevant person performed the letter-sending event. This is the so-called non-delegation reading.

$$
\begin{aligned}
& \left.\|\left.\right|_{\mathrm{v}_{2}^{\prime}} \operatorname{ziji}_{\mathrm{F}} \mathrm{v}_{1}^{\prime}\right]\left\|^{f}=\right\| \mathrm{ziji}_{\mathrm{F}}\left\|^{f}\left(\left\|\mathrm{v}_{1}^{\prime}\right\|^{f}\right)=\right\| \mathrm{ziji}_{\mathrm{F}} \|^{f}\left(\left\|\mathrm{v}_{1}^{\prime}\right\|^{o}\right) \\
& =\|\mathrm{ziji} F\|^{f}(\lambda x \lambda e \iota z[\operatorname{sent}(e) \wedge \operatorname{Agent}(e, x) \wedge \operatorname{Theme}(e, z) \wedge \operatorname{letter}(z)]) \\
& =\left\{\lambda x \lambda e \iota z[\operatorname{sent}(e) \wedge \operatorname{Agent}(e, y) \wedge \operatorname{Theme}(e, z) \wedge \operatorname{letter}(z)]: y \in D_{e / c}\right\}
\end{aligned}
$$

${ }^{10}$ Many sentences discussed in the paper are ambiguous. They can get various exclusive meanings, and the contextual domain will determine which meaning should be derived. (46a) is one of such sentences. Here, this sentence is used to illustrate the non-delegation reading, but this does not mean that it cannot get other exclusive readings. In fact, (46a) has all three of the exclusive readings. 
(48) $\|\left[{ }_{\mathrm{vP}}\right.$ John $\left.\mathrm{v}_{2}^{\prime}\right] \|^{f}$

$=\left\{\lambda e \iota z[\operatorname{sent}(e) \wedge \operatorname{Agent}(e, y) \wedge \operatorname{Theme}(e, z) \wedge \operatorname{letter}(z)]: y \in D_{k} e / c\right\}$

$=\{$ John sent the letter, Bill sent the letter, Mary sent the letter, ... $\}$, when $D_{e / c}=\{$ John, Bill, Mary, ... $\}$

It should be clarified what the term 'non-delegation reading' means. As illustrated above, when the domain $D_{e / c}$ in the focus semantic value of ziji contains different entities, such as $\{$ John, Bill, Mary, ... $\}$ in (48), the covert exhaustification will make the event true for the subject, but false for the other entities in the contextual domain. While the consideration of different possible individuals for some event often involves the accomplishment of some task, like the sending of a letter, nothing in the above derivation hinges on this particular type of events. So, the so-called non-delegation reading can be used for various events, like the event of sleeping on a bed. An example is provided in (49b), uttered in the context described in (49a).

(49) a. There were three people in John's family, namely John, John's wife, and their daughter. One day John bought a new bed, and he told his daughter that she could sleep on the bed beside her mom on the first day that the bed was moved to their house. However, John changed his mind later, and decided to sleep on the bed with his wife himself on that first day.

b. John ziji shui-le na zhang chuang.

John ZIJI sleep-PFV that CLF bed

'John slept on that bed himself.'

(49b) uttered in the above context is to express that John, rather than John's daughter, slept on the bed. As the predicate of sleeping on the bed is true for John, but not for his daughter, the so-called non-delegation reading is expressed.

Example (49) also illustrates the critical role of context restriction, which has been added to the focus semantics in Rooth (1992). In (49), the context is set in the way that $D_{e / c}$ contains only John and John's daughter, as in (50), and so the relevant propositions to be considered include only the two propositions in (51). Then after the application of the covert only-like operator, it is made false that John's daughter slept on the bed. Therefore, to utter (49b) in context (49a) is to make John's daughter false for the predicate of sleeping on the bed. Crucially, it does not make false John's wife for that predicate. So (49b) can be uttered when John was not the only person to have slept on the bed.

$$
\begin{aligned}
\left.\|\left.\right|_{\mathrm{v}_{2}^{\prime}} \operatorname{ziji}_{\mathrm{F}} \mathrm{v}_{1}^{\prime}\right] \|^{f} \\
=\left\{\lambda x \lambda e \iota z[\operatorname{sleep}(e) \wedge \operatorname{Agent}(e, y) \wedge \operatorname{Loc}(e, z) \wedge \operatorname{bed}(z)]: y \in D_{e / c}\right\}, \\
\quad \text { where } D_{e / c}=\{\operatorname{John}, \operatorname{John} \text { 's daughter }\}
\end{aligned}
$$


(51)
$\|$ lvP $\left._{\text {vohn }} \mathrm{v}_{2}^{\prime}\right] \|^{f}$
$=\{$ John slept on that bed, John's daughter slept on that bed $\}$

Surely (49b) can also express that only one person could sleep on the bed, and John decided to sleep there himself. This meaning should be uttered in another context where not only John's daughter but also his wife is considered for the sleeping event; accordingly, the set of propositions in the focus semantic value becomes \{John slept on that bed, John's daughter slept on that bed, John's wife slept on that bed\}. With the three propositions included, after exclusion, (49b) expresses that John, not the other two family members, slept on the bed. So, the exact meaning of (49b) depends on the setting of $D_{e / c}$ in the focus semantic value of ziji. Change of the contextual domain results in the change of meaning.

Change in the domain $D_{e / c}$ can also result in a change from one type of reading to another type of reading for ziji. Consider the context in (52).

(52) Suppose that John bought a new, large bed. The three people in John's family had planned to sleep together on that bed for the first day. However, John's mother-in-law was ill and so John's wife and their daughter went to visit her on that day that the bed was moved to their house. It then turned out that John slept on the bed alone that night.

(49b) can be uttered in scenario (52). When uttered, it expresses that John was the only one to have slept on the bed. This is the anti-group reading of ziji. This example reveals that the anti-group reading and the non-delegation reading differ only in what are included in $D_{e / c}$ in the focus semantic value of $z i j i$. In other words, in the anti-group reading of (49b), ziji still adjoins to $\mathrm{v}^{\prime}$, as shown in (53); moreover, ziji still denotes (45a) and (45b) for its ordinary semantic value and focus semantic value respectively. However, as the contextually relevant entities in (52) are John and the groups with John and his family member(s), as in (54a), the set of alternative propositions should be as in (54b). Therefore, after covert exhaustivity by the only-like operator, (49b) means that John slept on that bed, without any person accompanying him.

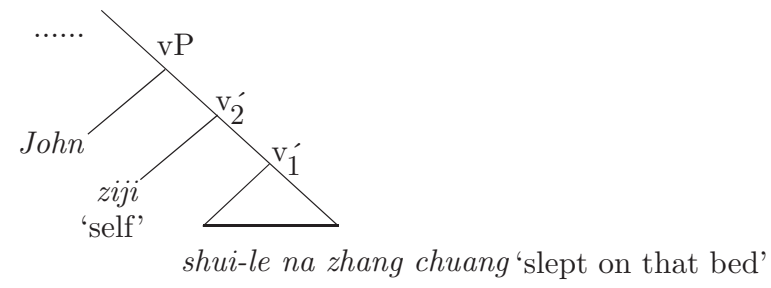

Acta Linguistica Academica 65, 2018 
(54) a. $\quad D_{e / c}=\{$ John, $\uparrow($ John $\oplus$ John's wife $), \uparrow($ John $\oplus$ John's daughter $)$, $\uparrow($ John $\oplus$ John's wife $\oplus$ John's daughter $)\}$

b. $\quad\left\|\left[\mathrm{vP}_{\mathrm{vP}} \mathrm{John} \mathrm{v}_{2}^{\prime}\right]\right\|^{f}$

$=\left\|\left[\mathrm{v}_{2} \quad \mathrm{ziji}_{\mathrm{F}} \mathrm{v}_{1}^{\prime}\right]\right\|^{f}\left(\|\mathrm{John}\|^{f}\right)$

$=\left\{\lambda x \lambda e \iota z[\operatorname{sleep}(e) \wedge \operatorname{Agent}(e, y) \wedge \operatorname{Loc}(e, z) \wedge \operatorname{bed}(z)]: y \in D_{e / c}\right\}(\operatorname{John})$

$=\left\{\lambda e \iota z[\operatorname{sleep}(e) \wedge \operatorname{Agent}(e, y) \wedge \operatorname{Loc}(e, z) \wedge \operatorname{bed}(z)]: y \in D_{e / c}\right\}$

$=\{$ John slept on that bed; John and John's wife slept on that bed; John and John's daughter slept on that bed; John, John's wife, and John's daughter slept on that bed\}

One may wonder why this alone-like reading should be an anti-group reading instead of an anti-plurality reading. It is seemingly possible to make the excluded alternatives be pluralities. For instance, it seems possible to set $D_{e / c}$ for the above case as the set $\{$ John, John $\oplus$ John's wife, John $\oplus$ John's daughter, John $\oplus$ John's wife $\oplus$ John's daughter $\}$, instead of what is shown in $(54 \mathrm{a})$. In this case no obvious problem arises from such a setting for $D_{e / c}$. However, there are examples against the evoking of pluralities by ziji. Consider (55) and (56).

(55) Scenario:

There was an individual assignment that every student in the math class should complete during the past weekend. On Monday, some student, who knew that Lisi had completed his own assignment, asked the question below:

Q: Nandao chule Lisi, hai-you shei ye xie-le zhe

could.it.be.said in.addition Lisi still-have who also write-PFV this

fen zuoye ma?

CLF assignment $\mathrm{Q}$

'Could it be said that, in addition to Lisi, someone else has also written the assignment?'

a. Meiyou, Lisi YI-GE-REN xie-le zhe fen zuoye. ${ }^{11}$

no Lisi one-CLF-person write-PFV this CLF assignment

'No, only Lisi has written the assignment.'

b. "Meiyou, Lisi ziji xie-le zhe fen zuoye.

no Lisi ZIJI write-PFV this CLF assignment

'\# No, Lisi has written the assignment by himself.'

${ }^{11}$ It is possible to not put stress on the expression yi-ge-ren 'one person'. However, if so, some people prefer to add the adverb ziyou 'only' to (55a). It is unknown why ziyou seems to be required for some people and seems to be so in many sentences with yi-ge-ren 'one person' for the anti-plurality meaning. 
(56) Scenario:

Everyone in the room was asked to take a sip of tea. Someone, who knew that Lisi had taken a sip, asked the question below:

Q: Nandao chule Lisi, hai-you shei ye he-le ma?

could.it.be.said in.addition Lisi still-have who also drink-PFV Q

'Could it be said that in addition to Lisi, someone else has also drunk it?'

a. Meiyou, Lisi YI-GE-REN he-le.

no Lisi one-CLF-person drink-PFV

'No, only Lisi has drunk it.'

b. "Meiyou, Lisi ziji he-le.

no Lisi ZIJI drink-PFV

'\# No, Lisi has drunk it by himself.'

(55a) and (56a) with the expression yi-ge-ren 'one person' are acceptable answers in (55) and (56) respectively, but (55b) and (56b) with the word $z i j i$ are not. Consider first (55). The question is asked to know who else, in addition to Lisi, has done the assignment. This is to consider the following possible plural agents for the predicate xie-le zhe fen zuoye 'wrote this assignment': Lisi $\oplus a, \operatorname{Lisi} \oplus b, \operatorname{Lisi} \oplus c, \ldots, \operatorname{Lisi} \oplus a \oplus b, \operatorname{Lisi} \oplus b \oplus c, \operatorname{Lisi} \oplus a \oplus c, \ldots$ (with the supposition that the students in the class include Lisi, $a, b, c, \ldots$ ). (55a) with yi-ge-ren 'one person' expresses that all the plural alternatives should not hold for the predicate, and thus conveys that Lisi is the only one to have done this individual assignment.

Interestingly, this anti-plurality meaning can be conveyed by yi-ge-ren 'one person' but not by ziji, shown by the unacceptability of (55b) in the context. The unacceptability can be explained if ziji evokes group alternatives. Crucially, in this context, students should do individual assignments, rather than group assignments. Thus the question in (55) is asked to know who has accomplished his/her own assignment, but not who has accomplished one assignment with Lisi. However if ziji evokes group alternatives, it will invite people to consider whether Lisi has accomplished an assignment by himself or collectively with some other people. This consideration is odd in this context. Thus, the use of ziji in (55b) is pragmatically odd.

The same thing is shown in (56). It is difficult to consider group alternatives for the individual action of taking a sip of tea; moreover, the question in (56) is not asked to know whether Lisi has taken a sip of tea by himself or collectively with someone else. So, the use of $z j i$ in (56b) is also problematic.

Further support for the grouping claim is seen in (57) and (58) below. 
(57) Zhangsan ziji xie-le zhe fen zuoye,

Zhangsan ZIJI write-PFV this CLF assignment

qita zu-yuan mei gen ta yiqi xie.

other group-member not with he together write

'Zhangsan wrote the assignment by himself; no other group members wrote

it with him.'

(58) Zhangsan ziji heguang-le zhe yi da bei cha,

Zhangsan ZIJI drink.up-PFV this one big cup tea

meiyou qita ren bangmang he.

no other person help drink

'Zhangsan drank this big cup of tea; no other person helped him for the drinking.'

In the two sentences, no contextual information rules out the consideration of whether Zhangsan has done something alone or collectively with someone else. Then the grouping proposal should predict that the two sentences can take ziji without problem. This prediction is correct. Therefore the paper concludes that for the alone-like interpretation, ziji should evoke group alternatives and convey an anti-group reading, rather than an anti-plurality reading.

So far, I have illustrated that ziji in the $\mathrm{v}^{\prime}$-adjoining position can derive the non-delegation reading or the anti-group reading, depending on whether the domain $D_{e / c}$ contains distinct entities or groups for exclusion. Next, I will discuss how the internal causation reading can be derived under a unified semantics of $z i j i$.

To derive the internal causation reading, let ziji adjoin to Cause'. An example is provided in (59), where sentence (59b) is assumed to have the structure in (59a). In (59a), chuan 'the boat' works not only as the theme undergoing the sinking event but also as a causer to make this event happen, a structure conforming to the internal causation analysis of anticausatives in Chierchia (2004) and Koontz-Garboden (2009). As a causer, chuan moves to [Spec, CauseP], leaving a co-indexed copy in its base generation position. I assume further that the semantics of the lower copy is a variable, and this variable will be bound later by an operator which binds the variable of the co-indexed upper copy. This assumption merely simplifies the semantic computation, though there are several other ways to deal with the interpretation of the two copies under the current semantics proposal of ziji. 
(59) a.

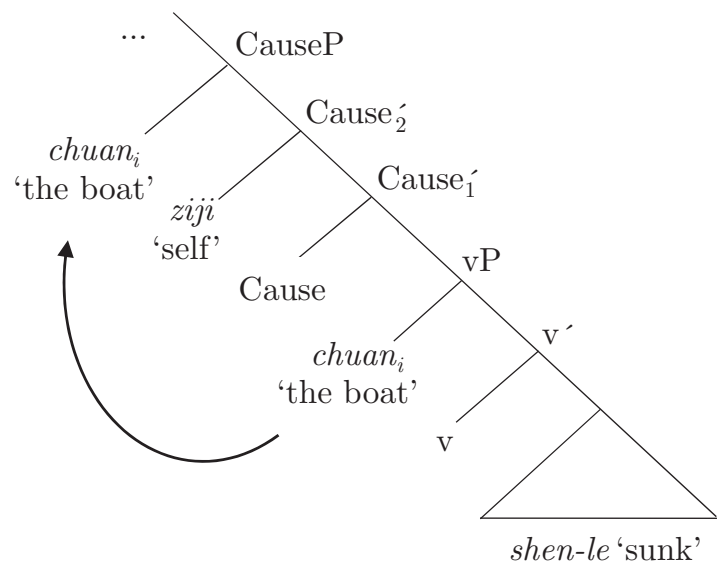

b. Chuan ziji shen-le.

boat ZIJI sink-PFV

'The boat sunk by itself.'

With all the assumptions made so far, the original semantic value of Cause' and that of sentence (59b) will be derived as shown in (60) and (61), respectively. Crucially, in the derivations, ziji is still an identity function for its original semantic value. Moreover, in (62), it keeps its focus semantic value presented in (45b) to derive the focus semantic value of Cause ${ }_{2}^{\prime}$. That is, it returns a set of functions such that each function in the set will take the NP in [Spec, CauseP] as its argument, but eventually make some $y$, some contextually relevant entity, be the causer of the letter sending event. With such a meaning for Cause $_{2}^{\prime}$, the alternative propositions to be considered for the final meaning will be a set of propositions which differ in causers, as in (63). Then after exclusion, sentence (59b) will get the meaning that the boat, instead of other contextually possible causers, caused the boat sink. This is the internal causation reading.

(60) $\|\left[_{\text {Cause }_{2}^{\prime}}\right.$ ziji Cause $\left._{1}^{\prime}\right] \|^{o}=$

$\|$ ziji $\left\|_{\mathrm{F}}\right\|^{o}\left(\|\right.$ Cause $\left._{1}^{\prime} \|^{o}\right)$

$=\left[\lambda P: P \in D_{\langle e,\langle\epsilon, t\rangle\rangle} \cdot P\right]\left(\|\right.$ Cause $\left._{1}^{\prime} \|^{o}\right)$

$=\|$ Cause $_{1}^{\prime} \|^{o}$

$=\lambda x \lambda e\left[\operatorname{Cause}(e, x) \wedge\|\mathrm{vP}\|^{o}(e)\right]$

$=\lambda x \lambda e[\operatorname{Cause}(e, x) \wedge[\operatorname{sink}(e) \wedge \operatorname{Theme}(e, z) \wedge \operatorname{boat}(z)]]$ 
(61) $\|{ }_{\text {CauseP }} \operatorname{chuan}_{i}$ Cause $\left._{2}^{\prime}\right] \|^{o}$

$=\left\|\operatorname{chuan}_{i}\right\|^{o}\left(\|\right.$ Cause $\left._{2}^{\prime} \|^{o}\right)$

$\left.=\lambda Q \lambda e[\iota z[\operatorname{boat}(z) \wedge Q(z)(e)]]\left(\lambda x \lambda e\left[\operatorname{Cause}(e, x) \wedge\|\mathrm{vP}\|^{o}(e)\right]\right]\right)$

$=\lambda e\left[\iota z\left[\operatorname{boat}(z) \wedge \operatorname{Cause}(e, z) \wedge\|\mathrm{vP}\|^{o}(e)\right]\right]$

$=\lambda e[\iota z[\operatorname{boat}(z) \wedge \operatorname{Cause}(e, z) \wedge \operatorname{sink}(e) \wedge \operatorname{Theme}(e, z)]]$

(62) $\|\left.\right|_{\text {Cause }_{2}^{\prime}}$ ziji $_{\mathrm{F}}$ Cause $\left._{1}^{\prime}\right] \|^{f}=$

$\left\|\mathrm{ziji}_{\mathrm{F}}\right\|^{f}\left(\|\right.$ Cause $\left._{1}^{\prime} \|^{f}\right)=$

$\|$ ziji $_{\mathrm{F}} \|^{f}\left(\|\right.$ Cause $\left._{1}^{\prime} \|^{o}\right)$

$=\left[\left\{\lambda P: P \in D_{\langle e,\langle\epsilon, t\rangle\rangle} \cdot \lambda x[P(y)]: y \in D_{e / c}\right\}\right]\left(\|\right.$ Cause $\left._{1}^{\prime} \|^{o}\right)$

$=\left\{\lambda x \lambda e[\operatorname{Cause}(e, y) \wedge[\operatorname{sink}(e) \wedge \operatorname{Theme}(e, z) \wedge \operatorname{boat}(z)]]: y \in D_{e / c}\right\}$

(63) $\|\left.\right|_{\text {CauseP }} \operatorname{chuan}_{i}$ Cause $\left._{2}^{\prime}\right] \|^{f}$

$=\left\|\operatorname{chuan}_{i}\right\|^{f}\left(\|\right.$ Cause $\left._{2}^{\prime} \|^{f}\right)$

$=\left\{\lambda e[\iota z[\operatorname{boat}(z) \wedge \operatorname{Cause}(e, y) \wedge \operatorname{sink}(e) \wedge \operatorname{Theme}(e, z)]]: y \in D_{e / c}\right\}$

$=\{$ the boat caused the boat to sink, the enemy caused the boat to sink, the general caused the boat to sink, ... $\}$, when $D_{e / c}=\{$ the boat, the enemy, the general, ...\}

In the internal causation reading, contextual restriction rooted in the use of $D_{e / c}$ also plays a critical role. This is shown in the use of (64).

(64) Men ziji kai-le.

door ZIJI open-PFV

'The door opened by itself.'

In the internal causation analysis, (64) should express that the door caused itself to open. However, the door is inanimate. If it was not opened by an animate agent, it must have been an electronic door, or it was open because of some natural force like wind. Importantly, in either case the utterance of (64) is fine. The common bewilderment is that wind should count as external force, and thus its presence as a causer is counter to the lack of external force conveyed by ziji. This puzzle can be explained by the use of $D_{e / c}$ in the current proposal. As illustrated in (60)-(63) for the boat-sinking example, ziji should evoke a set of propositions with different causers for (64), and the causers considered are restricted contextually. Therefore, it is possible to include in $D_{e / c}$ only the door and relevant animate entities in the context. As a result, the exclusion will make false these animate entities for the causer role. Therefore natural force like wind can still be an external causer in such a scenario to initiate the opening event, while some internal properties of the door, like its light weight, make the opening event realized. 


\subsection{The internal causation reading of ziji and the projection of CauseP}

The current analysis implies that CauseP is projected more prevalently than commonly assumed. Specifically under this analysis, the CauseP projection and the movement of the subject NP to its specifier position are determined by what role the subject NP should take for the event described. Take sentence (65) as an example. (65) is ambiguous. It can have the non-delegation reading as in (65a), the anti-group reading as in $(65 \mathrm{~b})$, or the internal causation reading as in $(65 \mathrm{c})$. The three readings are licensed in different contexts, with different alternatives considered and negated. For example, the question in (66a) licenses the non-delegation reading in (65a), which makes Zhansgan true but Lisi false for the homework-doing event. As for the anti-group reading in (65b), it is gotten when (65) is followed by (66b) for instance, and in this case the alternative made false should be the proposition that Zhangsan and Lisi did the assignment together. Finally, when (65) is followed by sentence (66c), the internal causation reading in $(65 \mathrm{c})$ is expressed that Zhangsan did the homework out of his volition and was not forced by anyone (e.g., his mother).

(65) Zhangsan ziji xie-le zuoye.

Zhangsan ZIJI write-PFV homework

a. 'Zhangsan, rather than some other person, did the homework.'

b. 'Zhangsan did the homework alone.'

c. 'Zhangsan did the homework out of his own will.'

(66) a. Did Lisi do the homework for Zhangsan?

b. He didn't do it with Lisi.

c. He was not forced by his mom.

Under my proposal, (65) builds the three readings on two available structures, (67) and (68). On the one hand, structure (67) may derive the non-delegation reading or the anti-group reading, depending on the contextual domain $D_{e / c}$.

(67) Structural representation for the non-delegation and the anti-group reading

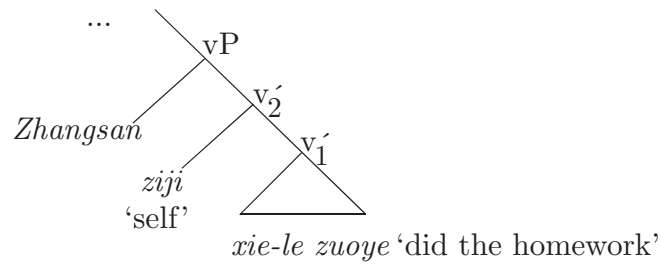


On the other hand, structure (68) derives the internal causation reading. The structure is used when it is to be conveyed that the entity denoted by the subject NP performs the action described out of his/her own will, like in the context of (66c). In this context, CauseP is projected and the subject NP moves to [Spec, CauseP].

(68) Structural for the internal causation reading

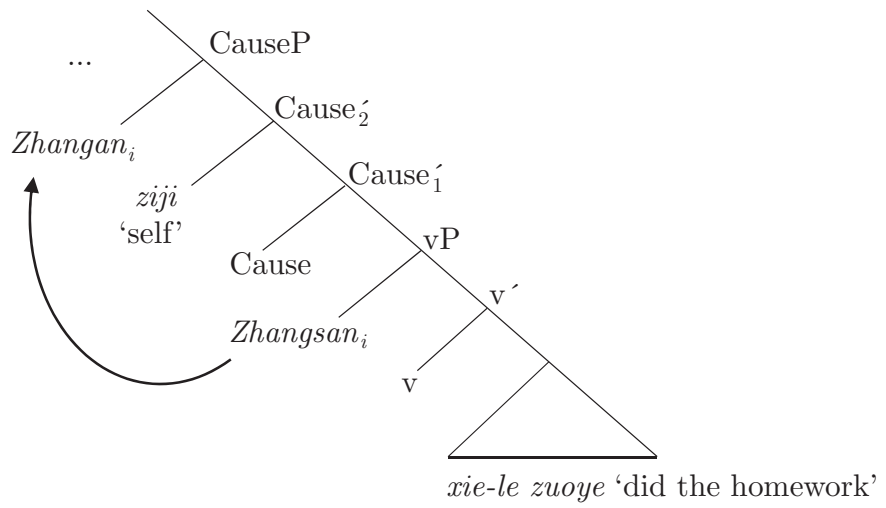

The above proposal for the internal causation reading is supported by the use of Hungarian maga. As shown in the introduction, Hungarian maga in the adverbial use works like Chinese ziji to possess all three exclusive readings. Therefore, the mechanism to derive the readings for Chinese ziji should work for Hungarian maga as well. Indeed for the internal causation reading, maga can express this reading not only for an inanimate entity as in (10), but also for an animate subject as in (69), where the boy referred to did the homework out of his own will.

(69) A fiú magá-tól csinálta meg a leckét.

the boy self-from made VERBAL.PARTICLE the homework-ACC

'The boy did his homework on his own initiative.' (so it was not because her mother told him to do his homework) (Tamás Halm, personal communication)

To further clarify the current analysis of the causation-related reading, let us compare (65) with (70B).

(70) A: Why did the boat sink? Did the army sink the boat?

$\mathrm{A}^{\prime}$ : Why did the boat sink? Did the army ask the boatman to sink the boat?

B: Bu-shi, chuanjia ziji shen-le chuan.

not-be boatman ZIJI sink-PFV boat

'No, the boatman sank the boat himself.' (as an answer to A)

'No, the boatman sank the boat on his own initiative.' (as an answer to $\mathrm{A}^{\prime}$ ) 
(70B) gets the non-delegation reading when it works as an answer to (70A); and it gets the internal causation reading when it is an answer to $\left(70 \mathrm{~A}^{\prime}\right)$. Under the current analysis, ziji derives the former reading under the structure of (71a) and the latter reading under the structure of (71b).

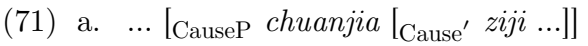

b. ... [CauseP chuanjia ${ }_{\uparrow}\left[\right.$ Cause' $^{\prime}$ ziji $\ldots .$. [CauseP chuanjia ${ }_{i}$....]]]

Under (71a), ziji derives the exclusive meaning that the boatman but not any other possible entities worked as the causer to sink the boat. This is a causer-related non-delegation reading, but not an internal causation reading. To derive an internal causation reading, a higher CauseP should be projected, and chuanjia 'the boatman' should move to the specifier position of this higher CauseP, as in (71b). Then when ziji evokes alternatives for consideration, the entities considered are different causers to make the boatman perform the boat-sinking action. Then ziji derives the internal causation reading that the boatman sank the boat by his own will, instead of being forced by the army.

The analysis proposed above offers a better understanding of when ziji expresses an internal causation reading and when CauseP is projected. First, this reading should be derived when it is reasonable to consider alternative possible causers. To illustrate, let us compare (65) with (49b).

While (65) is clearly ambiguous among the three readings, it is harder for (49b) to get the internal causation reading out of the blue. The contrast is due to the likelihood of considering alternative causers. For the predicate of doing homework in (65), it is natural to consider whether Zhangsan was forced to do homework or he did it out of his own initiative, since many kids may need to be forced to do homework. So it is reasonable to project CauseP and derive the internal causation reading. In contrast with the homework doing predicate, the predicate in (49b) is sleeping on a particular bed. If CauseP is projected and ziji adjoins to Cause', various causers should be considered for John's sleeping event on that particular bed. However, it is less common for someone to be forced to sleep on a particular bed. The consideration of various causers for such an event requires more context clues, like the identification of some possible causers in the context for the sleeping event. Without the clues, out of the blue it is more difficult for $(49 \mathrm{~b})$ to get the internal causation reading. In other words, even if the 
mechanism allows multiple readings for ziji-sentences, world knowledge and context will influence the availability of the readings. ${ }^{12}$

${ }^{12}$ It should be clarified that the current paper does agree that the syntactic position of ziji may affect the interpretation of its sentence. This is because in different positions, ziji may have different scope relations with items whose meanings are related to one's wishes or volition, and the interaction between ziji and such items could restrict the interpretations of ziji and result in different final sentence meanings. The interaction is arguably the reason why Tsai's (2015; to appear) inner-outer dichotomy of ziji is empirically correct to some extent. The sentence in (i), for instance, is one of the many examples supporting Tsai's generalization.

(i) Mama qiangpo Xiaoming (*ziji) yao (ziji) xie zuoye.

mother force Xiaoming self YAO self write homework

'Mother forced Xiaoming to do homework (by himself).'

This particular example has been provided by a reviewer to show that higher ziji but not lower ziji conveys a causation-related reading. However, due to limits of time and space, this paper cannot fully explain the uses of ziji in more complicated cases like (i). Instead, it will only provide a rough idea of how to deal with the interaction between ziji and a modal word like yao 'will/have to/want' (cf. Lin (2012) for the multiple meanings of yao). To explain the uses of ziji in (i), first consider sentences (ii) and (iii).

(ii) Xiaoming ziji yao xie zuoye. Shi ba?

Xiaoming self YAO write homework be $\mathrm{Q}$

'Xiaoming wants to do homework, without being forced by other people. Right?'

(iii) Xiaoming yao ziji xie zuoye.

Xiaoming YAO self write homework

'Xiaoming wants to/needs to do homework alone/by himself.'

When ziji scopes over the modal word yao, as in (ii), ziji seems to be in a syntactic position where it targets the ordering source of accessible possible worlds. It evokes the consideration of various possible ordering sources, resulting in the final meaning that the proposition 'Xiaoming does homework' is true in all accessible worlds which satisfy Xiaoming's desires, rather than in all accessible worlds where some other person's desires or some other rules are obeyed. In contrast, in (iii) ziji is in a lower position, where it seems to target the agent for the proposition 'Xiaoming does homework' and evokes the consideration of various possible agents. Subsequently, in the lower position, ziji conveys the non-delegation reading or the alone-like meaning, while in a position higher than yao, it emphasizes Xiaoming's intention to do homework. Then when ziji interacts with yao in (i), where the external force is indicated by the use of the main verb qiangpo 'force', the use of higher ziji rather than lower ziji will result in a semantic conflict. Although the above explanation lacks precise syntactic structure and semantic composition processes, it does show how the semantics of ziji might be affected by its syntactic position. 
The unified analysis of exclusive ziji also has an implication regarding the cause component in anticausatives. As mentioned, it is controversial whether anticausatives contain a cause component. In the literature, causation-related adjuncts, like by itself and from the earthquake in (72), are often used to support the existence of a cause component.

(72) a. The boat sank by itself.

b. The window broke from the earthquake.

But Rákosi (2012) examines the wide use of causation-related, ablativemarked adjuncts in Hungarian sentences like (73), arguing that a cause component does not exist in anticausatives originally, but are introduced by these adjuncts.

(73) Az ajtó magá-tól kinyílt.

the door.NOM itself-ABL open-PAST

'The door opened by itself.'

Rákosi's claim is dubious under the current analysis of exclusive ziji. Recall that Hungarian maga and Chinese ziji in adverbial uses work similarly to express various readings. When the current analysis is extended to Hungarian maga, this word should work like ziji to adjoin to Cause' ${ }^{\prime}$ or to $\mathrm{v}^{\prime}$, and the latter adjoining is linked to the non-delegation reading or the anti-group reading. Crucially in the mechanism proposed, maga does not require the Cause' adjunction. It is thus doubtful that it introduces the projection of CauseP. A more plausible analysis is that CauseP is projected first, and the presence of CauseP makes the adjoining of maga to Cause' $^{\prime}$ possible. When adjoined, it derives the internal causation reading for its sentence.

In sum, I have argued that Chinese adverbial ziji in its exclusive uses has a single unified semantics, and its surface meaning depends on what entities are included in the contextual domain $D_{e / c}$ and depends on which syntactic position ziji is located in. After showing how in principle all three readings can be derived from a unified semantics of ziji, I end this section by pointing out reading restrictions of some ziji-sentences. I use (64), repeated below, as an example.

$\left(64^{\prime}\right)$ Men ziji kai-le.

door ZIJI open-PFV

'The door opened by itself.' 
(64) only has the internal causation reading. This fact is a mystery. According to the above discussion, CauseP is projected independently of the use of ziji, and ziji does not always have to adjoin to Cause'. So it should be predicted that (64) can get the other exclusive readings of ziji. For example, in a scenario where Door $A$ was opened but door $B$ and door $C$ were not, it should be possible to utter (64) to express the so-called non-delegation reading that door $A$, rather than door $B$ or door $C$, was opened. However, (64) cannot convey this meaning. Likewise, the anti-group reading is also impossible for (64). That is, this sentence cannot express the meaning that only door $A$, among a group of doors, was opened.

In the next section, I will discuss unexpected restriction shown in cases like (64) for the use of exclusive ziji. In the end, I will propose that a presupposition has to be added to the use of ziji, and afterwards I will touch upon the structural issue of anticausatives again. I will argue that the added presupposition still cannot explain the stubborn internal causation reading shown in anticausatives like (64), and so I suggest the stubborn internal causation reading to be accounted for by the necessary projection of CauseP in anticausatives.

\section{Semantic restrictions of exclusive ziji and the structure of anticausatives}

\subsection{The presupposition and reading restrictions of $z i j i$}

The restriction of intensifiers in their uses or readings have been pointed out in several previous studies including Hole (2002), König \& Gast (2006), and Tsai (to appear). To explain this restriction, three different accounts have been proposed in the literature. The first is the agentivity constraint proposed in Hole (2002) and Tsai (to appear). This constraint can be illustrated by sentences (74) and (75) below.

(74) Die Berge [...] teilen das Land (\#? selbst) in zwei Teile.

'The mountains [...] divide the country into two parts (" themselves).'(Hole 2002, 136)

(75) Zhangsan ziji ku-le.

Zhangsan ZIJI cry-PFV

\#'Zhangsan, rather than some other person, cried.'

\#'Zhangsan cried alone.'

'Zhangsan cried without any identifiable reason.' 
Hole (2002) presents (74) to show that the use of the German adverbial intensifier selbst is problematic when this word associates with an inanimate or non-agent subject. Tsai (to appear) also points out the agentivity constraint for the use of inner Self, which is demonstrated by (75). Note that (75) cannot receive the non-delegation reading or the anti-group reading as shown in (75a) and (75b), respectively. In Tsai's account, the two readings are derived by inner Self, and the causation-related reading shown in $(75 \mathrm{c})$ is derived by outer Self. So the reading restriction of (75) tells us that outer Self but not inner Self can be used in this sentence. The reason, according to Tsai, is that the emotion-related predicate $k u$ 'cry' takes an experiencer subject, and with a non-agent verb, a comitant argument cannot be introduced for the use of inner Self, based on the following principle:

(76) Subject Agentivity on Inner Self

An agentive subject may license an optional comitative argument, which feeds into the focus construal of inner Self.

(Tsai to appear, 12)

Tsai uses (76) to make the existence of an agent subject a prerequisite to the use of inner Self. If an agent subject does not exist, a comitant role cannot be introduced. Without such a role, there is no way to derive a meaning related to this role. Therefore the alone-like reading of inner Self cannot be derived when ziji-sentences take non-agent subjects.

But the above account encounters at least two challenges. First, the account can only explain the difficulty of getting the alone-like reading, such as the lack of reading (75b) for sentence (75). The (non-)availability of the non-delegation reading, such as the interpretation in $(75 \mathrm{a})$, is ignored and unaccounted for.

Second, there are counterexamples of the agentivity constraint. Consider (77).

(77) Zhangsan ziji zai (fangjian) ku.

Zhangsan ZIJI progressive room cry

'Zhangsan is crying in the room alone.'

(77) and (75) both take the verb $k u$ 'cry'. With this predicate, the subject NP Zhangsan takes an experiencer role, instead of an agent role, and this sentence is predicted to get a causation-related reading only. But this is not true. This sentence gets an alone-like reading. So, the anti-group reading could be expressed by sentences with non-agent verbs. 
There are also counterexamples for the non-delegation reading. In (78), the predicate in speaker B's utterance is also ku 'cry', and so the subject NP daoyan 'the director' is not an agent either.

(78) A: The director asked the leading actress to cry. But what happened?

B: Daoyan ziji ku-le.

director ZIJI cry-PFV

'The director cried himself.'

This sentence expresses that the director, rather than the leading actress, cried. This is the so-called non-delegation reading. Therefore, even though out of the blue (75) only receives the internal causation reading, the context in (78) makes the non-delegation reading possible.

(79) is another example that shows how context helps make the non-delegation reading possible. While the passive sentence in (79a) sounds odd, this clause in $(79 \mathrm{~b})$ is perfect for the non-delegation reading that Zhangsan, rather than the one he planned to assassinate, was killed. This shows that passives with non-agent subjects can get the non-delegation reading as long as some contextual information is provided.

(79) a. 'Zhangsan ziji bei sha le.

Zhangsan ZIJI BEI kill PERFECT

'Zhangsan was killed himself.'

b. Zhangsan de cisha jihua shibai,

Zhangsan of assassination plan fail

zuihou daozhi Zhangsan ziji bei sha.

at.last cause Zhangsan ZIJI BEI kill

'Zhangsan's assassination plan failed, and therefore at last Zhangsan was killed himself.'

English adverbial $x$-self works the same way. For example, as discussed in Gast (2006), (80) with an unaccusative predicate fall may not get the non-delegation reading out of the blue. However, this reading is perfect in a context where John put a banana peel on the ground in order to make his secretary slip.

(80) John fell into the pit himself.

Since context can make the non-delegation reading possible for intensifiers, Gast concludes that subject agentivity does not truly exist as a semantic requirement for the reading/use restriction of intensifiers. 
While the agentivity constraint is too strong, adverbial intensifiers do show a clear tendency to co-occur with agent verbs for their non-delegation readings. The preference of agent verbs leads to another account for the restrictive uses/readings of intensifiers. In the account, the preference is claimed to be rooted in a semantic requirement related to its antecedent's involvement in an event. For example, compared with other possible alternative agents, the antecedent is required in Edmondson \& Plank (1978) to rank highest in a scale of direct involvement in the event denoted, and it is argued in Siemund (2000) to take a more central role in the event denoted. In a more recent work, Constantinou (2014) also argues for a semantic constraint along this line and uses event involvement and centrality to account for the restrictive use of adverbial exclusive intensifiers. A typical example to illustrate the account is shown in (81):

(81) A: Who built John's house?

B: John/ ${ }^{\#}$ Bill built his house himself.

In (81), speaker A asks a question about John's house, and in speaker B's response, John but not Bill can be the antecedent of the adverbial intensifier himself. The reason is as follows. If John is the antecedent, this individual will work not only as the agent of the event but also as the possessor of the object created. Then John will be more involved and take a more central role than Bill with respect to the event, because the latter could at most take an agent role in this event. Therefore John but not Bill is a suitable antecedent of the intensifier in (81).

Although the above event involvement/centrality constraint is proposed for English and German adverbial intensifiers, a similar restriction is shown in the use of Chinese ziji. For example, (82), the Chinese counterpart of (81), shows the same effect; that is, Zhangsan, the house owner, can be the antecedent of ziji in (82), but Lisi cannot.

(82) A: Shei gai-le Zhangsan de fangzi?

who build-PFv Zhangsan of house

'Who built Zhangsan's house?'

B: Zhangsan/" Lisi ziji gai-le fangzi.

Zhangsan/Lisi ZIJI build-PFV house

'Zhangsan built the house himself./" Lisi built the house himself.'

(82) clearly shows that the proposed semantics of ziji in Section 3.3 cannot be the whole story for this adverb. In that semantics analysis, ziji simply evokes contextually relevant alternatives, and the question and answer 
dialogue in (82) is a typical context to consider alternatives. So $(82 \mathrm{~B})$ is predicted to be good and get a non-delegation reading, no matter whether Zhangsan or Lisi is the subject. But this is not true, for (82B) cannot take Lisi. Note that the effect must come from ziji, since in the absence of ziji, the sentence Lisi gai-le fangzi 'Lisi built the house' is a perfect answer to the question in (82).

The above fact makes us infer that some semantic constraint must be added to the use of adverbial ziji. The question is whether the constraint about event involvement/centrality is the correct requirement. The answer is negative, in view of the following challenging cases.

First, there are cases where ziji does not seem to associate with the most central one among a set of alternatives, as (83) shows.
(83) A: Zhe ge xiaozu gongtong xie-wan-le
xiaozu zuoye ma?
this CLF group together write-complete-PFV group assignment $\mathrm{Q}$
'Did this group work together to finish the group assignment?'
$\mathrm{B}$ : Bu shi, Zhangsan ziji xie-wan-le xiaozu zuoye.
not be Zhangsan ZIJI write-complete-PFV group assignment
'No, Zhangsan finished the group assignment alone.'

The response in $(83 \mathrm{~B})$ is perfect with the reading that Zhangsan, rather than the whole group, finished the group assignment. Note that the assignment is for the whole group, and thus the whole group should rank higher than Zhangsan in the scale of event involvement/centrality. However, the intensifier ziji can associate with Zhangsan, a fact making the event centrality/involvement constraint dubious.

Second, there are cases where more than one alternative may work as the antecedent for the intensifier. Consider (78B), the answer daoyan ziji ku-le 'the director cried himself' again. In the answer, the director associates with ziji. It is inferred that the director ranks higher than other relevant alternatives for the crying event. This is a plausible ranking because the director is responsible for all the acting in this play, and can work as an experiencer and a causer for the crying event. But trickily, it is not impossible to answer the question in (78) by saying that zuihou nan zhujiao ziji ku le 'at last the leading actor cried himself', even though the leading actor does not appear to be more involved or to take a more central role in some way in the event than the director or the leading actress.

Since the event centrality/involvement constraint cannot provide a clear account for some cases, let us consider the third semantic constraint, which Gast (2006) proposes. 
Gast $(2006,118)$ claims that an adverbial exclusive intensifier not only evokes alternatives for consideration but also triggers a focus supposition that "the subject referent stands in some 'secondary thematic relation' to the event under discussion". Take (81) as an example. According to Gast's account, John can be the subject because in addition to an agent relation, he is related to the house-building event via a possession relation. In contrast with John, it is unclear how Bill may hold a secondary role in the house-building event, and so he fails to be the subject referent for (81). Besides this example, the subject referents in (79b) and (80) also work as causers for the events denoted in the licensing contexts. So, Gast's proposal correctly predicts that non-delegation readings in the two sentences are licensed in such contexts.

However, unfortunately Gast's proposal cannot work for adverbial ziji. The main problem is in the anti-group reading of ziji. Take (84) as an example.
Zhangsan ziji zai
da dianwan.

Zhangsan ZIJI progressive play video.game

'Zhangsan is playing video games alone.'

(84) expresses that Zhangsan is playing video games alone. For the event, Zhangsan works as the sole agent and he seems to work only as an agent. It is difficult to speculate what secondary thematic role Zhangsan should have also played in this event. Therefore, a secondary thematic role is not required for Chinese ziji.

From the above discussion, the paper concludes that all the three previous semantic constraints cannot account for the restrictive readings/uses of ziji. ${ }^{13}$ Some other constraint must be proposed.

Let us start to construct the proposal by going back to an important property of adverbial exclusive intensifiers emphasized in Hole (2002).

13 The paper uses Chinese data to argue against the event involvement/centrality constraint and Gast's focus supposition. If all exclusive intensifiers have the same semantics universally, the two constraints could not account for English and German intensifiers either. However, even though Chinese, English, and German exclusive intensifiers show similar behavior in the agentivity effect in (74)-(75), the effect of context licensing in (79b)-(80), and the restriction on the antecedent in (81)-(82), more data in English and German are still needed before any conclusion is drawn. As this paper aims to provide a unifying semantic analysis for the three readings of Chinese exclusive ziji, it will leave the study of intensifiers in other languages for future studies. 
(85) Hannes hat sein Auto selbst gewaschen.

'John washed his car himself.'

(86) a. Hannes hat sein Auto in einer Werkstatt waschen lassen.

'John had his car washed in a garage.'

b. Hannes hat seinen Sohn gebeten, sein Auto zu waschen.

'John asked his son to wash his car.'

c. Hannes' Auto ist in einer Werkstatt für ihn gewaschen worden.

'John's car was washed for him in a garage.'

d. Hannes' Sekretär hat sein Auto gewaschen.

'John's secretary washed his car.' (137-138)

As stated, intensifiers evoke alternative propositions for consideration. For sentence (85), any of the propositions in (86) may be considered as an alternative. What these alternative propositions have in common is that the individual named Hannes was involved with the car-washing event denoted by the VP. This is a crucial property of an adverbial exclusive intensifier that its antecedent must always be involved in the event denoted, no matter which alternative is considered. Note that this property is not about a ranking scale of event involvement/centrality. For example, in the alternative propositions in (86), Hannes was not always the most involved one in the event. The involvement can be somehow 'loose or indirect' (Hole $2002,138)$.

The above property of exclusive intensifiers brings us a useful hint to revise the semantics of ziji. The revision is shown in (87):

(87) Ordinary semantic value of $z i j i$ : (Final version)

$\left\|\mathrm{ziji}_{i}\right\|^{o}=\lambda P[P]$, only if $\forall y \exists e\left[\left[y \in D_{e / c} \wedge P(y)(e)\right.\right.$ at $\left.\left.t_{0}\right] \rightarrow \exists R\left[R\left(\left\|\mathrm{NP}_{i}\right\|, e\right)\right]\right]$

In the revised semantics, ziji still works as an identity function, but a presupposition is added to capture the above property. The presupposition can be described as follows in plain English: among $D_{e / c}$, the set of contextually relevant alternatives, no matter which one holds for the event denoted by $\mathrm{P}$ at the utterance time $\mathrm{t}_{0}$, there is some relation $\mathrm{R}$ holding between the event and the NP co-indexed with ziji. With this presupposition and the syntax setting that ziji is co-indexed with the NP in the specifier position of the phrase it adjoins to, the resulting effect is that the associate of ziji always holds some relation to the event denoted.

Let us discuss how this presupposition affects the use of ziji. As pointed out in Tsai (to appear), out of the blue the non-delegation reading and the anti-group reading for exclusive ziji are associated with agent verbs. This intuition can be accounted for by the presupposition. For sentences with 
agent verbs, it is easier to conjecture that the associate of ziji holds some relation to the event denoted, no matter which alternative among a set turns out to be the agent. Take (65), the sentence Zhangsan ziji xie-le zuoye 'Zhangsan ZIJI write-PFV homework', as an example. Consider first the anti-group reading under the supposition $D_{e / c}=\{$ Zhangsan, the group of Zhangsan and Lisi $\}$. In this case, no matter which alternative in $D_{e / c}$ turns out to be the agent of the homework-doing event, Zhangsan will hold an agent relation to the event. The presupposition in (87) is satisfied, and the sentence gets the anti-group reading without a problem. Next, consider the non-delegation reading. One easy way to satisfy the presupposition for this reading is to assume that the associate of ziji is the one assigned the assignment. If so, this individual will be relevant to this event via an affectee relation, no matter which person in $D_{e / c}$ does the homework. This account explains why the non-delegation reading is easy to get for (65), and under this reading, people do have the intuition that the homework belongs to Zhangsan. (82) can also be explained. In (82), as the house belongs to Zhangsan, Zhangsan but not Lisi is the one to always hold some relation to the house-building event. Therefore, the former but not the latter is a good associate of $z i j i$.

When sentences do not take agent verbs, it is harder to satisfy the presupposition. The sentence Zhangsan ziji ku-le 'Zhangsan ZIJI cry-PFV' in (75) is an example. Consider the non-delegation reading first. Suppose that $D_{e / c}$ is \{Zhangsan, Lisi $\}$. In this sort of setting, (75) should get the non-delegation reading that Zhangsan, rather than Lisi, has cried. However, to get this reading, the presupposition in (87) requires that Zhangsan, the associate of ziji, must hold some relation to the crying event, no matter whether Zhangsan or Lisi is the crying person. But if Lisi is the crying person, without further contextual information, it is unclear why Zhangsan should be relevant to Lisi's crying event. The same reasoning applies to other sentences with non-agent verbs. It is unclear why some individual remains relevant, no matter which person among a set is experiencing something or is in some state. Consequently, it is not easy to get the non-delegation reading out of the blue for such sentences.

The relation problem can be solved with the aid of context. For example, (78) contains the contextual information that the associate is a director, and he is responsible for the leading actress' crying action. The director then is relevant to the crying event even if the leading actress is the one to do the crying. The relation $\mathrm{R}$ in this case is a causation relation. (79b) can be accounted for in a similar fashion. The context provides the information that the associate of ziji functions as a causer. He then holds 
a relation to the killing event, no matter which person turns out to be killed. So in the context, this passive sentence can get the non-delegation reading.

The current account can also explain why sometimes more than one individual may be the associate of ziji, as in (78B), where the associate of ziji could be replaced by nan zhujiao 'the leading actor'. In an acting scene, it is not difficult to imagine that the leading actor is affected somehow, no matter whether the leading actress or the director does the crying. So in addition to the director, the leading actor is also a possible associate of ziji for the sentence.

Next, let us turn to the internal causation reading. A critical question is why sentences with non-agent subjects can easily get the internal causation reading. To answer this, take (75) as an example again. Under the internal causation reading, (75) expresses that Zhangsan caused his own crying, with other possible external causes excluded. Note that this is Zhangsan's crying. No matter what turns out to be the cause of the crying event, Zhangsan holds a theme relation to the crying event. The same point holds for all cases with the internal causation reading, because the caused event is always an event of the subject. The relation presupposition is trivially satisfied under this reading, and sentences with non-agent subjects have no problem receiving this reading.

Last but not least, let us move to the anti-group reading for sentences with non-agent verbs. As mentioned, this reading is hard to get. However, in contrast with the non-delegation reading, the presupposition in (87) is not responsible for the frequent absence of this reading. Take (75) as an example again, and suppose that $D_{e / c}$ is \{Zhangsan, the group of Zhangsan and Lisi\}. No matter which alternative turns out to be true for the crying event, Zhangsan is an experiencer in the event. It is quite easy to satisfy the presupposition under an anti-group reading.

What makes the anti-group reading difficult to get in these sentences is, I argue, the difficulty in considering group alternatives. For instance, crying is an individual action. It is not something to be accomplished by groups. Therefore, it is odd to consider group alternatives for the completion or inchoativity of a crying event. Without the consideration of group alternatives, an anti-group reading cannot be derived for ziji. This sort of reasoning can be applied to many other emotion-related or stative predicates. However, I do not mean that group alternatives cannot be considered at all. Group alternatives may be considered in at least three situations, as described below. 
First, people may intentionally plan to perform a collective crying action. When so, the subject of a crying predicate is an agent, and it is plausible to consider alternative group agents for the event.

Second, if something is expected to cause a group of people to cry simultaneously, the consideration of group alternatives is also plausible. An example is given in (88). Suppose that a group of people went to visit a haunted house, and visiting this scary place might cause the whole group of people cry together. In this context, ziji in (88B) conveys the anti-group meaning.

A: Guiwu name kepa, zheng zu ku-le ma?

haunted.house that scary whole group cry-PFV Q

'The haunted house is that scary. Did the whole group cry?'

B: Meiyou, qita ren mei ku, Zhangsan ziji ku-le.

no other person not cry Zhangsan ZIJI cry-PFV

'No, other people didn't cry. Zhangsan alone cried.'

Lastly, group alternatives can also be considered under another group meaning. To see this, let us discuss the use of together in (89). It is pointed out in Jayez \& Mari (2005) that English together can be used to convey various group senses. For example, (89) can be true not only in a scenario where John and Mary both conducted shoe-buying actions but also when Mary did nothing but stood beside John to accompany him during John's shoe-buying event. For the latter, the grouping involves each other's accompaniment rather than a collective action.

(89) John and Mary bought shoes together.

With this in mind, let us go back to (77), which conveys an anti-group reading of the latter sort. It is quite plausible to consider whether someone is accompanying Zhansgan when he is crying. So, group alternatives in the accompaniment sense are evoked and excluded for (77). ${ }^{14}$

In a word, group alternatives can be evoked and the anti-group reading can be conveyed for sentences with experiencer subjects, as long as it is plausible to evoke group alternatives and exclude them.

${ }^{14}$ It seems to be a general consensus that German and English exclusive intensifiers, namely selbst and $x$-self, do not express the anti-group reading (cf. Hole 2008; Constantinou 2014; among others). For example, Hole $(2008,292)$ points out that the use of selbst in sentence (i) below is infelicitous.

(i) Q: Did Ed and Paul paint the kitchen walls together?/Did Ed paint the kitchen walls together with Paul? 
After elaborating on how semantic reasons result in reading restrictions in many sentences with non-agent subjects, below the paper will return to anticausatives and argue that a pure semantics account cannot explain the reading restriction shown in these sentences.

\subsection{Implication on the structure of anticausatives}

As mentioned above, sentences with non-agent subjects do not necessarily stick to a causation reading, especially when the context helps them to get the other two readings. But if we go back to (64), the anticausative men ziji kai-le 'the door opened by itself', we find that it is extremely difficult, if not impossible, for anticausatives with inanimate subjects to get the non-delegation or the anti-group reading. The only way to get such readings is to change the inanimate property, such as to personify the door referred to in (64). The stubborn internal causation reading is a mystery, even if the relation presupposition in (87) is added to the semantics of exclusive ziji. To see how puzzling this phenomenon is, let us consider the anti-group reading.

As I have argued, the relation presupposition is a trivial requirement for the anti-group reading. When ziji-sentences cannot get this reading, the relation presupposition is never the reason. What affects the availability of
A: Nein, Ed hat es ALLEIN/" SELBST gemacht.
no Ed has it alone/self done
'No, Ed did it ALONE/ ${ }^{\#}$ HIMSELF.'

At the same time, these intensifiers are claimed to convey the 'without assistance' meaning, as expressed by speaker B's sentence below (cf. Eckardt 2001; Hole 2002; 2008; Constantinou 2014).

(ii) A: John built this house with Bill.

B: No, John built it himself.

(intended reading: 'without help'; Constantinou 2014, 97)

The above behavior of selbst/ $x$-self seems to suggest that the without assistance reading is different from the anti-group reading. If this is so, the current paper had better provide some way for $z i j i$ to derive the without assistance reading, in addition to the three readings discussed in the main text. However, it is unclear whether it is necessary to do so. As discussed in Jayez \& Mari (2005) in their study of English together, there are various group senses. Arguably, if A does something with the help of B, A and $\mathrm{B}$ can be viewed as being part of the same group for the event. And if this is so, the 'without assistance' reading is one sort of anti-group reading. Therefore, the paper will not try to derive an additional reading for ziji, and will leave the behavior of selbst/x-self in (i) and (ii) for future studies. 
this reading is whether it is plausible to evoke and consider group alternatives. Inanimate entities can still be grouped, like ships being grouped into different fleets. However, inanimate entities cannot intentionally do something or intentionally undergo some event collectively, nor can they form groups in the sense of accompaniment. Since it is not easy to evoke group alternatives for inanimate subjects, it is fair to attribute the absence of the anti-group reading in many of these anticausatives to semantic reasons. ${ }^{15}$

Nevertheless, not all cases can be accounted for by pure semantic accounts. Consider (90).

(90) A: Zaoshou menglie gongji zhihou, zheng ge jian-dui shen-le ma? encounter fierce attack after whole CLF ship-fleet sink-PFV Q 'After the fierce attack, did the whole fleet of ships sink?'

B: Meiyou, qita chuan mei shen, ( ${ }^{? ?}$ zhe sao chuan ziji shen-le.) no other ship not sink this CLF ship ZIJI sink-PFV 'No, other ships didn't sink; ('? this ship sunk by itself).'

(90) is in contrast with (88). What is exemplified by (88) is the following: when some external force might cause the predicate described to hold for a group of entities simultaneously, it is plausible to consider group alternatives. As for (90), the enemy intended to sink the whole fleet of ships, making it plausible for ziji to evoke the whole fleet of ships as a group alternative. As the context strongly suggests an anti-group reading, and $z i j i$ is able to express this reading in so many sentences in Chinese, some people may not entirely reject an anti-group interpretation for (90B). But there is a clear contrast: this reading in (90B) is not as perfect as in

${ }^{15}$ A reviewer has correctly pointed out that there are cases where ziji-sentences with inanimate subject NPs can receive the anti-group reading, as in the following example provided by the reviewer.

(i) Q: Yi Nimizihao hangmu wei shou de jiandui dida le ma? by Nimitz aircarrier as head DE fleet arrive PFV Q 'Has the fleet led by the aircraft carrier Nimitz arrived?'

A: Meiyou, Nimizihao ziji xian dida, qita zhanjian hai mei dida. no Nimitz ziji first arrive other battleship still no arrive

'No, the aircraft carrier Nimitz has arrived by itself; other battleships haven't.'

Such examples, however, are not real counterexamples to the stubborn internal causation generalization for ziji-sentences with inanimate subject NPs. Note that vehicles are driven and controlled by animate human beings. Conceptually it is possible to treat the actions of these vehicles as those of animate entities. When this is so, it is not surprising that the anti-group reading can be received. 
(88B). With an inanimate subject NP, ziji in (90B) seems to resist an anti-group reading. It tends to uphold an internal causation reading. As a result, the dialogue in (90) becomes a bit odd. It is expressed that the enemy intended to attack the whole fleet, but it did not sink the other ships, and this ship sunk by itself.

As the stubborn reading restriction of ziji in (90B) cannot be accounted for semantically, I suggest that it is explained by a structurerelated account; that is, the reading restriction is rooted in the necessary projection of CauseP in anticausatives. When CauseP is projected, the clause zhe sao chuan shen-le 'this ship sunk' has the structure in (91). To derive the non-delegation reading or the anti-group reading, ziji should adjoin to $\mathrm{v}^{\prime}$ and evoke contextually relevant entities as alternatives to undergo the sinking event. Suppose that the asserted ship is ship A, and consider two possible values for $D_{e / c}$ : $\{$ ship A, ship B, ship C $\}$ and $\{$ ship $\mathrm{A}$, the whole fleet $\}$. With $z i j i$ adjoining to $\mathrm{v}^{\prime}$, the alternative propositions triggered for the two values of $D_{e / c}$ should be as in (92) and (93) respectively. But ship A is inanimate. It should not take the causer role to make various ships or fleets sink. The triggering of such alternative propositions is problematic, and therefore ziji should not adjoin to $\mathrm{v}^{\prime}$ in these cases.

(91) [CauseP the $\operatorname{ship}_{i}\left[{ }_{\mathrm{vP}}\right.$ the $\left.\left.\operatorname{ship}_{i}\left[\mathrm{v}_{\mathrm{v}^{\prime}} \operatorname{sunk}\right]\right]\right]$

(92) $\{$ Ship $A$ caused ship $A$ to $\operatorname{sink,~Ship~} A$ caused ship $B$ to $\operatorname{sink,~Ship~} A$ caused ship $C$ to $\operatorname{sink}\}$

(93) \{Ship $A$ caused ship $A$ to sink, Ship $A$ caused the whole fleet to sink\}

In contrast, if ziji adjoins to Cause' in the structure of (91), different causers for the sinking of ship A will be considered, as in (94):

(94) $\{$ Ship $A$ caused ship $A$ to sink, the enemy caused ship $A$ to sink, ... $\}$

There is nothing pragmatically wrong for this set of alternative propositions, and so ziji may adjoin to Cause ${ }^{\prime}$ and derive the internal causation reading. In the end, this reading becomes the only one available. Therefore, ziji in anticausatives with inanimate subjects always gets the internal causation reading. ${ }^{16}$

${ }^{16}$ Inanimacy is a key factor in the lack of the non-delegation reading or the anti-group reading in anticausatives. So, an alternative analysis is to attribute the lack of these readings directly to inanimacy, probably due to some lexical requirement or some other unknown semantic reason. As it remains unclear what could be the alternative account, the attempt for a pure semantic account will be left for future studies. 


\section{Conclusion}

The paper starts from the examination of the three readings of the Chinese adverbial ziji, namely the non-delegation reading, the anti-group reading, and the internal causation reading. By cross-linguistic and semantic similarities, it argues for a unified semantics of exclusive ziji, and shows how this item varies its meanings through the change of the contextual domain $D_{e / c}$ and its adjoining position.

After outlining the basic proposal, the paper explains reading restrictions shown in many ziji-sentences. It claims that a relation presupposition should be added to the semantics of ziji. It also points out that context, world knowledge, and the plausibility of evoking and excluding some alternatives may affect reading availability of ziji-sentences.

The mechanism and the detailed semantic accounts presented here reveal issues related to CauseP. The paper proposes that CauseP, at least for internal causation, is projected more prevalently than commonly assumed. When the subject should take not only an agent/theme role but also a causer role for the event described, CauseP is projected and this subject NP moves upward to [Spec, CauseP]. The paper also argues that in the mechanism proposed, Chinese ziji and Hungarian maga do not always adjoin to Cause', and thus it is unlikely that CauseP is introduced by these causation-related adjuncts. Instead, from the stubborn reading restriction shown for ziji, the paper infers that CauseP always projects in anticausatives.

The paper has presented a precise mechanism and has explained how a reflexive marker with a unified semantics expresses various exclusive readings, including the crucial internal causation readings. If this analysis is on the right track, it will give us a new perspective to consider intensifiers and the projection of CauseP, and it will also help us to take one step further in the study of anticausatives.

\section{References}

Alexiadou, Artemis, Elena Anagnostopoulou and Florian Schäfer. 2006a. The fine structure of (anti-)causatives. In C. Davis, A. R. M. Deal and Y. Zabbal (eds.) Proceedings of nels 36. Amherst, MA: CLSA. 115-128.

Alexiadou, Artemis, Elena Anagnostopoulou and Florian Schäfer. 2006b. The properties of anticausatives crosslinguistically. In M. Frascarelli (ed.) Phases of interpretation. Berlin \& New York: Mouton de Gruyter. 187-21. 
Alexiadou, Artemis, Elena Anagnostopoulou and Florian Schäfer. 2015. External arguments in transitivity alternations: A layering approach. Oxford: Oxford University Press.

Beavers, John and Andrew Koontz-Garboden. 2013a. Complications in diagnosing lexical meaning: A rejoinder to Horvath and Siloni (2013). Lingua 134. 210-218.

Beavers, John and Andrew Koontz-Garboden. 2013b. In defense of the reflexivization analysis of anticausativization. Lingua 131. 199-216.

Belletti, Adriana. 2004. Aspects of the low IP area. In L. Rizzi (ed.) The structure of CP and IP. Oxford: Oxford University Press. 16-51.

Belletti, Adriana. 2005. Extended doubling and the VP periphery. Probus 17. 1-35.

Centineo, Giulia. 1995. The distribution of si in Italian transitive/inchoative pairs. In M. Simons and T. Galloway (eds.) Proceedings of the 5th Semantics and Linguistics Conference (SALT V). Ithaca, NY: CLC Publications, Cornell University. 54-71.

Chierchia, Gennaro. 2004. A semantics for unaccusatives and its syntactic consequences. In A. Alexiadou, E. Anagnostopoulou and M. Everaert (eds.) The unaccusativity puzzle. Oxford: Oxford University Press. 22-59.

Chierchia, Gennaro, Danny Fox and Benjamin Spector. 2012. The grammatical view of scalar implicatures and the relationship between semantics and pragmatics. In C. Maienborn, K. von Heusinger and P. Portner (eds.) Semantics: An international handbook of natural language meaning. Volume 2. Walter de Gruyter: Berlin \& Boston. 2297-2332.

Cinque, Guglielmo. 1995. Italian syntax and universal grammar. Cambridge: Cambridge University Press.

Cinque, Guglielmo. 1999. Adverbs and functional heads: A cross-linguistic perspective. Oxford: Oxford University Press.

Constantinou, Harris. 2014. Intensifiers: Meaning and distribution. Doctoral dissertation. University College London.

Dowty, David R. 1979. Word meaning and Montague grammar: The semantics of verbs and times in generative syntax and in Montague's PTQ. Dordrecht: Reidel.

Eckardt, Robert. 2001. Reanalysing selbst. Natural Language Semantics 9. 371-412.

Edmondson, Jonathan and Frans Plank. 1978. Great expectations: An intensive self analysis. Linguistics and Philosophy 2. 373-413.

Ernst, Thomas. 2002. The syntax of adverbs. Cambridge: Cambridge University Press.

Ernst, Thomas. 2014. Adverbial adjuncts in Mandarin Chinese. In C.-T. J. Huang, L.-H. A. Li and A. Simpson (eds.) The handbook of Chinese linguistics. Malden, MA \& Oxford: John Wiley \& Sons. 49-72.

Gast, Volker. 2002. The grammar of identity. Intensifiers and reflexives as expressions of an identity function. Doctoral dissertation. Free University of Berlin.

Gast, Volker. 2006. The grammar of identity. Intensifiers and reflexives in Germanic languages. New York: Routledge.

Grahek, Sabina. 2009. Internal causation in Slovene: Constructions with the morpheme se and Experiencer datives. Leeds Working Papers in Linguistics and Phonetics 14. $16-48$.

Haider, Hubert. 2004. Pre- and post-verbal adverbials in OV and vO. Lingua 114. 779-807. 
Hale, Kenneth and Samuel Jay Keyser. 1993. On argument structure and the lexical expression of syntactic relations. In K. Hale and S. J. Keyser (eds.) The view from building 20. Essays in linguistics in honor of Sylvain Bromberger. Cambridge, MA: MIT Press. 53-109.

Heine, Bernd. 2000. Polysemy involving reflexive and reciprocal markers in African languages. In Z. Frajzyngier and T. S. Curl (eds.) Reciprocals: Forms and functions. Amsterdam \& Philadelphia: John Benjamins. 1-29.

Hole, Daniel. 2002. Agentive selbst in German. In G. Katz, S. Reinhard and P. Reuter (eds.) Sinn und Bedeutung VI: Proceedings of the 6th Annual Meeting of the Gesellschaftfar Semantik. Osnabrück: Institute of Cognitive Science. 133-150.

Hole, Daniel. 2005. Agentive selbst and other instantiations of the identity function in German. Manuscript, Ludwig Maximilians Universität München.

Hole, Daniel. 2008. Focus on identity: The dark side of ziji. Linguistic Review 26. 267-295.

Horvath, Julia and Tal Siloni. 2011. Causatives across components. Natural Language \& Linguistic Theory 29. 657-704.

Horvath, Julia and Tal Siloni. 2013. Anticausatives have no cause(r): A rejoinder to Beavers and Koontz-Garboden. Lingua 131. 217-230.

Huang, C.-T. James and Luther Chen-Sheng Liu. 2001. Logophoricity, attitudes and ziji at the interface. In P. Cole, G. Hermon and C.-T. J. Huang (eds.) Long-distance reflexives (Syntax and Semantics 33). San Diego: Academic Press. 141-195.

Jayez, Jacques and Alda Mari. 2005. Togetherness. In E. Maier, C. Bary and J. Huitink (eds.) Proceedings of Sinn und Bedeutung 9. Nijmegen: University of Nijmegen. $155-169$.

Kemmer, Suzanne. 1993. The middle voice: A typological and diachronic study. Amsterdam \& Philadelphia: John Benjamins.

Keyser, Samuel Jay and Thomas Roeper. 1984. On the middle and ergative constructions in English. Linguistic inquiry 15. 381-416.

König, Ekkehard. 1991. The meaning of focus particles: A comparative perspective. London: Routledge.

König, Ekkehard. 2001. Intensifiers and reflexives. In M. Haspelmath, E. König, W. Österreicher and W. Raible (eds.) Language typology and language universals. An international handbook/Sprachtypologie und sprachliche Universalien. Ein internationales Handbuch/La typologie des langues et les universaux liguistiques. Manuel international (Handbücher zur Sprach- und Kommunikationswissenschaft 20.1). Berlin \& New York: Walter de Gruyter. 747-760.

König, Ekkehard and Volker Gast. 2002. Reflexive pronouns and other uses of self-forms in English. Zeitschrift für Anglistik und Amerikanistik 50. 225-238.

König, Ekkehard and Volker Gast. 2006. Rethinking the relationship between intensifiers and reflexives. Linguistics 44. 343-381.

König, Ekkehard and Peter Siemund. 2000. Intensifiers and reflexives: A typological perspective. In Z. Frajzyngier and T. S. Curl (eds.) Reflexives: Form and functions (Typological Studies in Language 40). Amsterdam \& Philadelphia: John Benjamins. 41-74.

Koontz-Garboden, Andrew. 2009. Anticausativization. Natural Language and Linguistic Theory 27. $77-138$. 
Kratzer, Angelika. 1996. Severing the external argument from its verb. In J. Rooryck and L. Zaring (eds.) Phrase structure and the lexicon. Dordrecht: Kluwer. 109-137.

Kratzer, Angelika. 2005. Building resultatives. In C. Maienborn and A. Wöllstein-Leisten (eds.) Event arguments in syntax, semantics and discourse. Tübingen: Niemeyer. $178-212$.

Lakoff, George. 1968. Some verbs of change and causation. In S. Kuno (ed.) Mathematical linguistics and automatic translation (Report NSF-20). Cambridge, MA: MIT Press. $1-27$.

Lakoff, George. 1970. Irregularity in syntax. New York: Holt, Rinehart \& Winston.

Landman, Fred. 1989. Groups I. Linguistics and Philosophy 12. 559-605.

Landman, Fred. 2000. Events and plurality: The Jerusalem lectures. Dordrecht: Kluwer.

Levin, Beth and Malka Rappaport Hovav. 1995. Unaccusativity. At the syntax-lexical semantics interface. Cambridge, MA: MIT Press.

Liao, Fang-Chun. 2017. The semantics of adverbial ziji in Mandarin. MA thesis. National Chiao Tung University.

Lin, T.-H. Jonah. 2012. Multiple-modal constructions in Mandarin Chinese and their finiteness properties. Journal of Linguistics 48. 151-186.

Link, Godehard. 1984. Hydras: On the logic of relative constructions with multiple heads. In F. Landman and F. Veltman (eds.) Varieties of formal semantics: Proceedings of the Fourth Amsterdam Colloquium. Dordrecht: Foris. 245-257.

Manzini, M. Rita and Leonardo M. Savoia. 2001. The syntax of object clitics: si in Italian dialects. In G. Cinque and G. Salvi (eds.) Current studies in Italian syntax: Essays offered to Lorenzo Renzi. Amsterdam: North Holland. 233-264.

Manzini, M. Rita and Leonardo M. Savoia. 2011. (Bio)linguistic variation: Have/be alternations in the present perfect. In A. M. D. Sciullo and C. Boeckx (eds.) The biolinguistic enterprise: New perspectives on the evolution and nature of the human language faculty. Oxford: Oxford University Press. 222-265.

Markman, Vita. 2003. Causatives without causers and Burzio's generalization. In K. Moulton and M. Wolf (eds.) Proceedings of NELS 34. Amherst: University of Massachusetts. 425-439.

Medová, Luci. 2012. Anticausatives are derived unergatives. In M. Ziková and M. Dočekal (eds.) Slavic languages in formal grammar. Proceedings of FDSL 8.5, Brno 2010. Frankfurt am Main: Peter Lang. 291-306.

Moravcsik, Edith. 1972. Some cross-linguistic generalisations about intensifier constructions. In P. M. Peranteau, J. L. Levi and G. C. Phares (eds.) The Chicago Which Hunt: Papers from the Relative Clause Festival. papers from the Eighth Regional Meeting of the Chicago Linguistic Society. Chicago: Chicago Linguistic Society. $271-277$.

Nelson, Diane. 2000. Linking causatives and experiencers. Leeds Working Papers in Linguistics 8. 149-177.

Nilsen, Øystein. 2004. Domains for adverbs. Lingua 114. 809-847.

Pan, Haihua. 1997. Constraints on reflexivization in Mandarin Chinese. New York: Garlan.

Parsons, Terence. 1990. Events in the semantics of English: A study in subatomic semantics. Cambridge, MA: MIT Press. 
Pesetsky, David. 1995. Zero syntax: Experiencers and cascades. Cambridge, MA: MIT Press.

Pylkkänen, Liina. 1999. The syntax of internal and external causation. In Proceedings of the Texas Linguistics Society. Conference: Perspectives on Argument Structure. Austin, TX: University of Texas.

Pylkkänen, Liina. 2002. Introducing arguments. Doctoral dissertation. Massachusetts Institute of Technology.

Pylkkänen, Liina. 2008. Introducing arguments. Cambridge, MA: MIT Press.

Rákosi, György. 2012. In defence of the non-causative analysis of anticausatives. In M. Everaert, M. Marelj and T. Siloni (eds.) The theta system: Argument structure at the interface. Oxford: Oxford University Press. 177-199.

Ramchand, Gillian. 2008. Verb meaning and the lexicon: A first phase syntax. Cambridge: Cambridge University Press.

Rizzi, Luigi. 1997. The fine structure of the left periphery. In L. Haegeman (ed.) Elements of grammar. Dordrecht: Kluwer. 281-337.

Rooth, Mats. 1985. Association with focus. Doctoral dissertation. University of Massachusetts, Amherst.

Rooth, Mats. 1992. A theory of focus interpretation. Natural Language Semantics 1. $75-116$.

Schäfer, Florian. 2007. By itself. Manuscript. Universität Sttutgart.

Schäfer, Florian. 2008. The syntax of (anti-)causatives: External arguments in change-ofstate contexts. Amsterdam \& Philadelphia: John Benjamins.

Schäfer, Florian and Margot Vivanco. 2016. Anticausatives are weaker scalar expressions, not reflexive expressions. Glossa 1. 1-36.

Siemund, Peter. 2000. Intensifiers in English and German. A comparison. New York \& London: Routledge.

Tang, Chih-Chen Jane. 1989. Chinese reflexives. Natural Language and Linguistic Theory 7. $93-121$.

Travis, Lisa. 2000. Event structure in syntax. In C. L. Tenny and J. Pustejovsky (eds.) Events as grammatical objects: The converging perspectives of lexical semantics and syntax. Stanford: CSLI Publications. 145-185.

Tsai, Wei-Tien Dylan. 2015. A tale of two peripheries: Evidence from Chinese adverbials, light verbs, applicatives and object fronting. In W.-T. D. Tsai (ed.) The cartography of Chinese syntax. Oxford: Oxford University Press. 1-32.

Tsai, Wei-Tien Dylan. to appear. Causality, comitativity, contrastivity, and selfhood. In J. Hu and H. Pan (eds.) Interfaces in grammar. Amsterdam \& Philadelphia: John Benjamins.

Williams, Edwin. 1981. Argument structure and morphology. The Linguistic Review 1. $81-114$ 